\title{
Robust Monetary Policy Rules with Unknown Natural Rates
}

\author{
Athanasios Orphanides \\ Board of Governors of the Federal Reserve System \\ and \\ John C. Williams* \\ Federal Reserve Bank of San Francisco
}

December 2002

\begin{abstract}
We examine the performance and robustness properties of alternative monetary policy rules in the presence of structural change that renders the natural rates of interest and unemployment uncertain. Using a forward-looking quarterly model of the U.S. economy, estimated over the 1969-2002 period, we show that the cost of underestimating the extent of misperceptions regarding the natural rates significantly exceeds the costs of overestimating such errors. Naive adoption of policy rules optimized under the false presumption that misperceptions regarding the natural rates are likely to be small proves particularly costly. Our results suggest that a simple and effective approach for dealing with ignorance about the degree of uncertainty in estimates of the natural rates is to adopt difference rules for monetary policy, in which the short-term nominal interest rate is raised or lowered from its existing level in response to inflation and changes in economic activity. These rules do not require knowledge of the natural rates of interest or unemployment for setting policy and are consequently immune to the likely misperceptions in these concepts. To illustrate the differences in outcomes that could be attributed to the alternative policies we also examine the role of misperceptions for the stagflationary experience of the 1970s and the disinflationary boom of the 1990s.
\end{abstract}

KEYWORDS: Inflation targeting, policy rules, natural rate of unemployment, natural rate of interest, misperceptions.

JEL Classification System: E52

Correspondence: Orphanides: Federal Reserve Board, Washington, D.C. 20551, Tel.: (202) 452-2654, e-mail: Athanasios.Orphanides@frb.gov. Williams: Federal Reserve Bank of San Francisco, 101 Market Street, San Francisco, CA 94105, Tel.: (415) 974-2240, e-mail: John.C.Williams@sf.frb.org.

* Prepared for the September 2002 Brookings Panel on Economy Activity. We benefited from presentations of earlier drafts at the European Central Bank, the Deutsche Bundesbank, The Johns Hopkins University, and the University of California, Santa Cruz. This research project has benefited from discussions with Bill Brainard, Flint Brayton, Richard Dennis, Thomas Laubach, Andy Levin, David Lindsey, Jonathan Parker, Mike Prell, George Perry, Dave Reifschneider, John Roberts, Glenn Rudebusch, Bob Tetlow, Bharat Trehan, Simon van Norden, Volker Wieland, and Janet Yellen. We thank Mark Watson, Bob Gordon, and Robert Shimer for kindly providing us with updated estimates. Kirk Moore provided excellent research assistance. Any remaining errors are are the sole responsibility of the authors. The opinions expressed are those of the authors and do not necessarily reflect views of the Board of Governors of the Federal Reserve System or the management of the Federal Reserve Bank of San Francisco. 
"The natural rate is an abstraction; like faith, it is seen by its works. One can only say that if the bank policy succeeds in stabilizing prices, the bank rate must have been brought in line with the natural rate, but if it does not, it must not have been." (Williams, 1931, p. 578)

\section{Introduction}

The conventional paradigm for the conduct of monetary policy calls for the monetary authority to attain its objectives of a low and stable rate of inflation and full employment by adjusting its short-term interest rate instrument-in the United States, the federal funds rate - in response to economic developments. In principle, when aggregate demand and employment fall short of the economy's natural levels of output and employment, or when other deflationary concerns appear on the horizon, the central bank should ease monetary policy by bringing real interest rates below the natural rate of interest for some time. Conversely, the central bank should respond to inflationary concerns by adjusting interest rates upward so as to bring real interest rates above the natural rate. In this setting, the natural rate of unemployment is the unemployment rate consistent with stable inflation; the natural rate of interest is the real interest rate consistent with the unemployment rate being at its natural rate and, therefore with stable inflation. ${ }^{1}$ In carrying out this strategy in practice, the policymaker would ideally have accurate, quantitative, contemporaneous readings of the natural rate of interest and the natural rate of unemployment. Under those circumstances, economic stabilization policy would be relatively straightforward.

However, an important difficulty that complicates policymaking in practice and may limit the scope for stabilization policy, however, is that policymakers do not know the values of these natural rates in real time, that is, when they make policy decisions. Indeed, even in hindsight there is considerable uncertainty regarding the natural rates of unemployment and interest, and ambiguity about how best to model and estimate natural rates. Milton Friedman, arguing against natural rate-based policies in his AEA presidential address, posited that "One problem is that [the policymaker] cannot know what the 'natural' rate is. Unfortunately, we have as yet devised no method to estimate accurately and read-

\footnotetext{
${ }^{1}$ This definition leaves open the question of the length of the horizon over which one defines stable inflation. Rotemberg and Woodford (1999), Woodford(2002), and Neiss and Nelson (2001), among others, consider definitions of the natural rates whereby inflation is constant in every period while many other authors (cited later in this paper) examine estimates of a lower frequency or "trend" natural rates.
} 
ily the natural rate of either interest or unemployment. And the 'natural' rate will itself change from time to time." (Friedman, 1968, p. 10). Friedman's comments echo those made decades earlier by Williams (1931, quoted above) and Cassel (1928), who wrote of the natural rate of interest: "The bank cannot know at a certain moment what is the equilibrium rate of interest of the capital market." Even earlier, Wicksell (1898) who stressed that "the natural rate is not fixed or unalterable in magnitude" (p. 106). Recent research using modern statistical techniques to estimate the natural rates of unemployment, output, and interest indicate that this problem is no less relevant today than it was 35,75 , or 105 years ago.

These measurement problems appear to be particularly acute in the presence of structural change when natural rates may vary unpredictably, making estimates of the natural rates subject to increased uncertainty. Staiger, Stock, and Watson (1997a) document that estimates of a time-varying natural rate of unemployment are very imprecise (see also Staiger, Stock, and Watson 1997b and Laubach 2001). Orphanides and van Norden (2002) show that estimates of the related concept of the natural rate of (or potential) output are likewise plagued by imprecision (see also Lansing 2002). Similarly, Laubach and Williams (2002) document the great degree of uncertainty regarding estimates of the natural rate of interest. These difficulties have led some observers to discount the usefulness of natural rate estimates for policymaking. Brainard and Perry (2000) conclude "that conventional estimates from a NAIRU [nonaccelerating-inflation rate of unemployment] model do not identify the full employment range with a degree of accuracy that is useful to policymaking." (p. 69). Staiger, Stock, and Watson suggest a reorientation of monetary policy away from reliance on the natural rate of unemployment, noting that

a rule in which monetary policy responds not to the level of the unemployment rate but to recent changes in unemployment without reference to the NAIRU (and perhaps to a measure of the deviation of inflation from a target rate of inflation) is immune to the imprecision of measurement that is highlighted in this paper. An interesting question is the construction of formal policy rules that account for the imprecision of estimation of the NAIRU. (Staiger, Stock, and Watson, 1997a, p. 249) 
This question, coupled with the related issue of mismeasurement of the natural rate of interest, is the focus of this paper.

We employ a forward-looking quarterly model of the U.S. economy to examine the performance and robustness properties of simple interest rate policy rules in the presence of real-time mismeasurement of the natural rates of interest and unemployment. Our work builds on an active literature that has explored the implications of mismeasurement for monetary policy, including Orphanides (1998, 2001, 2002a), Smets (1998), Wieland (1998), Orphanides et al (2000), McCallum (2001), Rudebusch (2001, 2002), Ehrmann and Smets (2002), and Nelson and Nikolov (2002). A key aspect of our investigation is the recognition that policymakers may be uncertain as to the true data-generating processes describing the natural rates of unemployment and interest and the extent of the mismeasurement problem that they face. As a result, standard applications of certainty equivalence based on the classical linear-quadratic-Gaussian control problem do not apply. ${ }^{2}$ To get a handle on this difficulty, we compare the properties of policies optimized to provide good stabilization performance across a large range of alternative estimates of natural rate mismeasurement. We then examine the costs of basing policy decisions on rules that are optimized with incorrect baseline estimates of mismeasurement, that is, rules that attempt to properly account for the presence of uncertainty regarding the natural rates but inadvertently overestimate or underestimate the magnitude of the problem.

These robustness exercises point to a potentially important asymmetry with regard to possible errors in the design of policy rules attempting to account for natural rate uncertainty. We find that the costs of underestimating the extent of natural rate mismeasurement significantly exceeds the costs of overestimating it. Adoption of policy rules optimized under the false presumption that misperceptions regarding the natural rates are likely to be small proves particularly costly in terms of stabilizing inflation and unemployment. By comparison, the inefficiency associated with policies incorrectly based on the presumption that misperceptions regarding the natural rates are likely to be large tends to be relatively modest. As a result, when policymakers do not possess a precise estimate of the magnitude of misperceptions regarding the natural rates, a robust strategy is to act as if the

\footnotetext{
${ }^{2}$ See Swanson (2000) and Svensson and Woodford (2002) for recent expositions of certainty equivalence in the absence of any model uncertainty. Hansen and Sargent (2002) offer a modern treatment of robust control in the presence of possible model misspecification.
} 
uncertainty they face is greater than their baseline estimates suggest it may be. We show that overlooking these considerations can easily result in policies with considerably worse stabilization performance than anticipated.

Our results point towards an effective, simple strategy that is a robust solution to the difficulties associated with natural rate misperceptions. This is to adopt, as guidelines for monetary policy, difference rules in which the short-term nominal interest rate is raised or lowered from its existing level in response to inflation and changes in economic activity. These rules, which do not require knowledge of the natural rates of interest and unemployment and are consequently immune to likely misperceptions in these concepts, emerge as the solution to a robust control exercise from a wider family of policy rule specifications. Although these rules are not "optimal" in the sense of delivering first-best stabilization performance under the assumption that policymakers have precise knowledge of the form and magnitude of uncertainty they face, they are robust in that they effectively ensure against major mistakes when such knowledge is not held with great confidence.

Finally, our results suggest that some important historical differences in monetary policy and macroeconomic outcomes over the past forty or so years can be traced to differences to the formulation of monetary policy that closely relate to the treatment of the natural rates. As we illustrate, misperceptions regarding the natural rates, importantly due to the steady increase in the natural rate of unemployment, could have contributed to the stagflationary outcomes of the 1970s. Paradoxically, a policy that would be optimal at stabilizing inflation and unemployment if the natural rates of unemployment and interest were known can account for such dismal outcomes in a period when natural rates were rising. In contrast, our analysis suggests that had policy followed a robust rule that ignores information about the levels of natural rates during the 1970s, economic outcomes could have been considerably better. Conversely, outcomes during the disinflationary boom of the 1990s appear consistent with a policy closer to our robust rule. The natural rate of unemployment apparently drifted downward significantly during the second half of the decade, which might have resulted in deflation had policymakers pursued the policy that real-time assessments of the natural rates might have dictated. In the event, policymakers during the mid- and late 1990s avoided this pitfall. 


\section{Policy in the Presence of Uncertain Natural Rates}

As a starting point, we look at the nature of the problem in the context of a generalization of the simple policy rule proposed by John Taylor (1993) ten years ago. Let $f_{t}$ denote the federal funds rate, $\pi_{t}$ the rate of inflation, and $u_{t}$ the rate of unemployment, all measured in quarter $t$. The Taylor rule can then be expressed by

$$
f_{t}=\hat{r}_{t}^{*}+\pi_{t}+\theta_{\pi}\left(\pi_{t}-\pi^{*}\right)+\theta_{u}\left(u_{t}-\hat{u}_{t}^{*}\right)
$$

where $\pi^{*}$ is the policymaker's inflation target and $\hat{r}_{t}^{*}$ and $\hat{u}_{t}^{*}$ are the policymaker's estimates of the natural rates of interest and unemployment, respectively. Note that here we consider a variant of the Taylor rule that responds to the unemployment gap instead of the output gap for our analysis, recognizing that the two are related by Okun's (1962) law. ${ }^{3}$ As is well known, rules of this type have been found to perform quite well in terms of stabilizing economic fluctuations, at least when the natural rates of interest and unemployment are accurately measured. In his 1993 exposition, Taylor examined response parameters equal to $1 / 2$ for inflation gap and the output gap, which, using an Okun's coefficient of 2 , corresponds to setting $\theta_{\pi}=0.5$ and $\theta_{u}=-1.0$. We also consider a revised version of this rule with double the responsiveness of policy to the output gap $\left(\theta_{u}=-2.0\right.$ in our case), which Taylor (1999b) found to yield improved stabilization performance relative to his original rule.

The promising properties of rules of this type were first reported in the Brookings volume edited by Bryant, Hooper and Mann (1993) which offered detailed comparisons of the stabilization performance of various interest rate-based policy rules in several macroeconometric models. The contributions in Taylor (1999a), as reviewed in Taylor (1999b), provided additional support for this finding. However, historical experience suggests that policy guidance from this family of rules may be rather sensitive to misperceptions regarding the natural rates of interest and unemployment. The experience of the 1970s, discussed in Orphanides (2000a, 2000b, 2002a), offers a particularly stark illustration of policy errors that may result.

We explore two dimensions along which the Taylor rule has been generalized that in combination offer the potential to mitigate the problem of natural rate mismeasurement.

\footnotetext{
${ }^{3}$ In what follows, we assume that an Okun's law coefficient of 2 is appropriate for mapping the output gap to the unemployment gap. This is significantly lower that Okun's original suggestion of about 3.3. Recent views, as reflected in the work by various authors place this coefficient in the 2 to 3 range.
} 
The first aims to mitigate the effects of mismeasurement of the natural rate of unemployment by partially (or even fully) replacing the response to the unemployment gap with one to the change in the unemployment rate. This modification parallels that made by McCallum (2001), Orphanides (2000b), Orphanides et al. (2000), Leitemo and Lonning (2002), and others, who have argued in favor of policy rules that respond to the growth rate of output rather than the output gap when real-time estimates of the natural rate of output are prone to measurement error. Although in general it is not a perfect substitute for responding to the unemployment gap directly, responding to the change in the unemployment rate is likely to be reasonably effective because it calls for a easing of policy when unemployment is rising and tightening when unemployment is falling. ${ }^{4}$ The second dimension we explore is incorporation of policy inertia, represented by the presence of the lagged short-term interest rate in the policy rule. As shown by Williams (1999), Levin et al. (1999, 2002), Rotemberg and Woodford (1999) and others, rules that exhibit a substantial degree of inertia can significantly improve the stabilization performance of the Taylor rule in forward-looking models. The presence of inertia in the policy rule also reduces the influence of the estimate of the natural rate of interest on the current setting of monetary policy and, therefore, the extent to which misperceptions regarding the natural rate of interest affect policy decisions. To see this, consider the generalized Taylor rule of the form

$$
f_{t}=\theta_{f} f_{t-1}+\left(1-\theta_{f}\right)\left(\hat{r}_{t}^{*}+\pi_{t}\right)+\theta_{\pi}\left(\pi_{t}-\pi^{*}\right)+\theta_{u}\left(u_{t}-\hat{u}_{t}^{*}\right)+\theta_{\Delta u}\left(u_{t}-u_{t-1}\right) .
$$

The degree of policy inertia is measured by $\theta_{f} \geq 0$; cases where $0<\theta_{f}<1$ are frequently referred to as "partial adjustment"; the case of $\theta=1$ is termed a "difference rule" or "derivative control" (Phillips 1954), whereas $\theta_{f}>1$ represents superinertial behavior (Rotemberg and Woodford 1999). These rules nest the Taylor rule as the special case when $\theta_{f}=\theta_{\Delta u}=0 .^{5}$

To illustrate more precisely the difficulty associated with the presence of misperceptions regarding the natural rates of unemployment and interest it is useful to distinguish the real-time estimates of the natural rates, $\hat{u}_{t}^{*}$ and $\hat{r}_{t}^{*}$, available to policymakers when policy

\footnotetext{
${ }^{4}$ Interestingly, as Woodford (1999) has shown, the optimal policy from a "timeless perspective" in the purely forward-looking "new synthesis" model responds to the change in the output gap, but not to its level.

${ }^{5}$ Policy rules that allow for a response to the lagged instrument and the change in the output gap or unemployment rate as in equation (2) have been found to offer a simple characterization of historical monetary policy in the United States for the past few decades in earlier studies (Orphanides 2002b, Orphanides and Wieland 1998, McCallum and Nelson 1999, and Levin et al 1999, 2002).
} 
decisions are made, from their "true" values $u^{*}$ and $r^{*}$. If policy follows the generalized rule given by equation (2), then the "policy error" introduced in period $t$ by misperceptions in period $t$ is given by

$$
\left(1-\theta_{f}\right)\left(\hat{r}_{t}^{*}-r^{*}\right)+\theta_{u}\left(\hat{u}_{t}^{*}-u_{t}^{*}\right)
$$

Although unintentional, these errors could subsequently induce undesirable fluctuations in the economy, worsening stabilization performance. The extent to which misperceptions regarding the natural rates translate into policy induced fluctuations depends on the parameters of the policy rule. As is evident from the expression above, policies that are relatively unresponsive to real-time assessments of the unemployment gap, that is, those with small $\theta_{u}$ minimize the impact of misperceptions regarding the natural rate of unemployment. Similarly, inertial policies with $\theta_{f}$ near unity reduce the direct effect of misperceptions regarding the natural rate of interest. That said, inertial policies also carry forward the effects of past misperceptions of the natural rates of interest and unemployment on policy, and one must take account of this interaction in designing policies robust to natural rate mismeasurement.

One policy rule that is immune to natural rate mismeasurement of the kind considered here is a "difference" rule, in which $\theta_{f}=1$ and $\theta_{u}=0:^{6}$

$$
f_{t}=f_{t-1}+\theta_{\pi}\left(\pi_{t}-\pi^{*}\right)+\theta_{\Delta u}\left(u_{t}-u_{t-1}\right) .
$$

We note that this policy rule is as simple, in terms of the number of parameters, as the original formulation of the Taylor rule. In addition, this rule is certainly simpler to implement in practice than the Taylor rule, because it does not require knowledge of the natural rates of interest or unemployment. However, because this type of rule ignores potentially useful information about the natural rates of interest and unemployment, its performance relative to the Taylor rule and the generalized rule will depend on the degree of mismeasurement and the structure of the model economy, as we explore below. It is also useful to note that this rule is closely related to price-level and nominal income targeting rules, stated in first-difference form.

\footnotetext{
${ }^{6}$ This specification is similar to those examined by Judd and Motley (1992) and Fuhrer and Moore (1995b), in which the change in the short-term rate responds to the growth of nominal income or to inflation, respectively.
} 


\section{Historical Estimates of Natural Rates}

Considerable evidence suggests that the natural rates of unemployment and interest vary significantly over time. In the case of the unemployment rate, a number of factors have been put forward as underlying time variation, including changing demographics, changes in the efficiency of job matching, changes in productivity, effects of greater openness to trade, and the changing rates of disability and incarceration (Shimer 1998, Katz and Krueger 1999, Ball and Mankiw 2002). However, a great deal of uncertainty surrounds the magnitude and timing of these effects on the natural rate of unemployment. Similarly, the natural rate of interest is likely influenced by variables that appear to change over time, including the rate of trend income growth, fiscal policy, and household preferences, as discussed in Laubach and Williams (2002). But the factors determining the natural rate of interest are not directly observed, and the quantitative relationship between them and the natural rate remains poorly understood.

Even with the benefit of hindsight and "best practice" techniques, our knowledge about the natural rates remains cloudy, and this situation is unlikely to improve in the foreseeable future. Staiger, Stock, and Watson (1997a) highlight three types of uncertainty regarding natural rate estimates. For estimated models with deterministic natural rates, sampling uncertainty related to the imprecision of estimates of model parameters is one source of uncertainty. Sampling uncertainty alone yields 95 percent confidence intervals with widths between 2 and 4 percentage points for the natural rate of unemployment (Staiger, Stock, and Watson 1997a), and between 3 and 4 percentage points for the natural rate of interest (Rudebusch 2001, Laubach and Williams 2002). Allowing the natural rate to change unpredictably over time adds an another source of uncertainty; for example, the 95 percent confidence intervals for a stochastically time-varying natural rate of interest is over 7 percentage points, twice that associated with a constant natural rate. Finally, there is considerable uncertainty and disagreement about the most appropriate approach of modeling and estimating natural rates, and this model uncertainty implies that the confidence intervals based on any one particular model may understate the true degree of uncertainty that policymakers face. Importantly for the analysis in this paper, policymakers cannot be confident that their natural rate estimates are efficient or consistent, but most realistically 
must make due with imperfect modeling and estimating methods.

Of course, in practice, policymakers are at an even greater disadvantage than the econometrician who attempts to estimate natural rates retrospectively, because policymakers must act on "one-sided," or real-time natural rate estimates, which are based only on the data available at the time the decision is made. As documented below, such estimates typically are much noisier than the smooth retrospective, or "two-sided," estimates generally reported in the literature. For a given model, the difference between the one-sided and two-sided estimates provides an estimate of natural rate misperceptions resulting from the real-time nature of the policymaker's problem.

To illustrate the extent of these measurement difficulties, we provide comparisons of retrospective and real-time estimates of the natural rates of unemployment and interest. The various measures correspond to alternative implementations of two basic statistical methodologies that have been employed in the literature: univariate filters and multivariate unobserved- components models. The univariate filters separate the cyclical component of a series from its secular trend and use the latter as a proxy of the natural level of the detrended series. Univariate filters possess the advantages that they impose very little structure on the problem and are relatively simple to implement. Because multivariate methods bring additional information to bear on the decomposition of trend and cycle, they can provide more accurate estimates of natural rates assuming that the underlying model is correctly specified. However, there is a great degree of uncertainty about model misspecification, especially regarding the proper modeling of low-frequency behavior, and as a result the theoretical benefits from multivariate methods may be illusory in practice.

We examine two versions each of two popular univariate filters, the Hodrick-Prescott (1997) filter (HP) and the Band-Pass filter (BP) described by Baxter and King (1999). For the HP filter, we consider two alternative implementations, one with the smoothness parameter $\lambda=1,600$, the value most commonly used in analyzing quarterly data, and one with $\lambda=25,600$ which smoothes the data more and is also closer to the approach advocated by Rotemberg (1999). Application of the BP filter requires a choice of the range of frequencies identified as associated with the business cycle, which are to be filtered from the underlying series. We examine two popular alternatives, an 8-year window favored by Baxter and King (1999) and Christiano and Fitzgerald (2002) and a 15-year window 
employed by Staiger, Stock and Watson (2002) to estimate a "trend" for the unemployment rate. We apply these four univariate filters to obtain both one-sided (real time) and twosided (retrospective) estimates of the natural rates of unemployment and interest.

We also obtain estimates of the natural rates based on two multivariate unobserved components models, and we offer comparisons with models similar to those proposed by other authors. These models suppose that the "true" processes for the natural rates of interest and unemployment can be reasonably modeled as random walks:

$$
\begin{aligned}
& u_{t}^{*}=u_{t-1}^{*}+\eta_{u, t} \quad \eta_{u} \sim \mathrm{N}\left(0, \sigma_{\eta_{u}}^{2}\right), \\
& r_{t}^{*}=r_{t-1}^{*}+\eta_{r, t} \quad \eta_{r} \sim \mathrm{N}\left(0, \sigma_{\eta_{r}}^{2}\right) .
\end{aligned}
$$

For the natural rate of unemployment, we implement a Kalman filter model, similar to those in Staiger, Stock, and Watson (1997a, 2002) and Gordon (1998), to estimates a time-varying NAIRU rate from an estimated Phillips curve. ${ }^{7}$ (In what follows, we treat the NAIRU and the natural rate of unemployment as synonymous.) We also examine estimates following the procedure detailed by Ball and Mankiw (2002). These authors posit a simple accelerationist Phillips curve relating the annual change in inflation to the annual unemployment rate. They estimate the natural rate of unemployment be applying the HP filter to the residuals from this relationship.

For the natural rate of interest, we apply the Kalman filter to an equation relating the unemployment gap and the real interest rate gap (the difference between the real federal funds rate and the natural rate of interest). The basic specification and methodology are close to that used by Laubach and Williams (2002), but we assume that the natural rate of interest follows a random walk, whereas they allow for an explicit relationship between the natural rate and the estimated trend growth rate of GDP. The basic identifying assumption is that the unemployment gap converges to zero if the real rate gap is zero. Thus, stable inflation in this model is consistent with both the real interest rate and the unemployment rate equaling their respective natural rates. $^{8}$

\footnotetext{
${ }^{7}$ In the measurement equation, the inflation rate depends on lags of inflation with the unity sum restriction on the coefficients, relative oil and non-oil import price inflation, and the unemployment rate gap. We apply Stock and Watson's (1998) median unbiased estimator for the signal-to-noise ratio and estimate the remaining parameters by maximum likelihood over the sample period 1969:1-2002:2.

${ }^{8}$ In two papers, Bomfim uses other approaches to estimate the natural rate of interest. Bomfim (2001) uses yields on indexed bonds to estimate investors' view of the natural rate of interest; unfortunately, these
} 
As noted above, these multivariate approaches to estimating natural rates are subject to specification error and therefore the resulting estimates may be inefficient or inconsistent. For example, the models used for estimating the natural rate of unemployment impose the accelerationist restriction that the sum of the coefficients on lagged inflation in the inflation equation equals unity. But as Sargent (1971) demonstrated, reduced-form characterizations of the Phillips curve consistent with the natural rate hypothesis do not necessarily imply this restriction and imposing it is invalid. A very different view, which likewise comes to the conclusion that these models are misspecified, is provided by Modigliani and Papademos (1975), who view the Phillips curve as a structural relationship but, instead of imposing the natural rate hypothesis, propose the concept of a "noninflationary rate of unemployment, or NIRU" (p. 145) Following this approach, Brainard and Perry (2000) report estimates of the natural rate of unemployment when the assumption of constant parameters and the accelerationist restriction are relaxed.

Retrospective estimates of the natural rate of unemployment exhibit variation over time and across methods at given points in time. Table 1 reports estimates for the natural rate using the methods described above as well as the most recent Congressional Budget Office $(2001,2002)$ NAIRU estimates, the Kalman filter-based NAIRU estimates in Staiger, Stock, and Watson (2002) and Gordon (2002), and Shimer's (1988) estimates based on demographic factors. All of these estimates are two-sided in the sense that they use data over the whole sample period to arrive at an estimate for the natural rate at any given past quarter. Figure 1 plots a representative set of these estimates over 1969-2002; for comparison, the average rate of unemployment over that period was nearly 6 percent.

The retrospective estimates share a common pattern: generally they are relatively low at the end of the 1960s, rise during the late 1960s and 1970s, and trend downward thereafter, reaching levels in the late 1990s similar to those in the late 1960s. However, these estimates also exhibit substantial dispersion at most points in time, indicating that, even in hindsight, precisely identifying the natural rate of unemployment is quite difficult. For example, the estimates for both 1970 and 1980 cover a 2-percentage point range.

As stressed above, the estimates of the natural rate of unemployment that are relevant

securities have only been in existence for a relatively short time so we have scant time series evidence using this approach. In earlier work, Bomfim (1997) estimated a time-varying natural rate of interest using the Federal Reserve Boards's MPS model. 
for setting policy are not those shown in Table 1 and Figure 1 but rather the one-sided estimates that incorporate only information available at the time. Figure 2 shows the one-side estimates for a range of the methods described above. In the case of the univariate filters, the reported series are constructed from the estimates of the trend at the last available observation at each point in time. In the case of the multivariate filters, the natural rate estimates are likewise based only on observed data, but the estimates of the model parameters are from data for the full sample. Given the relative imprecision of the estimates of many of the latter estimates, the true real-time estimates in which all model parameters are estimated using only data available at the time are likely to be considerably worse than the one-sided estimates reported here.

A striking feature of univariate filter real-time estimates is how much more closely they track the actual data than do the smooth, retrospective estimates reported in Figure 1. This excess sensitivity of univariate filters to final observations is a well known problem (see e.g. St. Amant and van Norden (1998), Christiano and Fitzgerald (2001), Orphanides and van Norden (2002), and van Norden (2002)). Evidently, these filters have difficulty distinguishing between cyclical and secular fluctuations in the underlying series until the subsequent evolution of the data becomes known. This problem is less evident in the multivariate filters where the natural rate estimate is updated based on inflation surprises as opposed to movements in the unemployment rate itself.

Figures 3 and 4 plot a set of two-sided and one-sided estimates, respectively, of the natural rate of interest. Throughout this paper, the real interest rate is constructed as the difference between the federal funds rate and ex post rate of inflation (based on the GDP price index). Each figure shows two multivariate estimates (our Kalman filter estimate described above as well as that from Laubach and Williams $\left.(2002)^{9}\right)$ and estimates from the same univariate filters used for the natural rate of unemployment. As in the case of the natural rate of unemployment, the various techniques yield a broad range of possible retrospective and real-time estimates of the natural rate of interest over time.

Given the wide dispersion in these natural rate estimates, especially the more policyrelevant one-sided estimates, a natural question is whether one can discriminate between

\footnotetext{
${ }^{9}$ Laubach and Williams (2002) construct the real interest rate using the inflation rate of personal consumption expenditure prices; we have adjusted their natural rate estimates to place them on the basis of GDP price inflation.
} 
the methods based on their empirical usefulness in predicting inflation and unemployment. To test the forecasting performance of methods using the natural rate of unemployment, we compare inflation forecast errors using a simple Phillips curve model in which inflation depends on four lags of inflation, the lagged change in the unemployment rate, and two lags of the unemployment gap based on the various one-sided estimates of the natural rate of unemployment. We also consider the performance of a simple fourth-order autoregressive, or $\mathrm{AR}(4)$, inflation forecasting equation without any unemployment rate terms. For this exercise, we use the revised data current as of this writing. As seen in the upper part of Table 2, the equations that include the unemployment gap outperform (that is, have a lower forecast standard error than) the $\operatorname{AR}(4)$ specification, but inflation forecasting accuracy is virtually identical across the specifications that include the unemployment gaps. ${ }^{10}$ To test the forecasting performance of methods using the natural rate of interest, we apply the same basic procedure to a simple unemployment equation, where the unemployment rate depends on two lags of itself and the lagged real rate gap. This yields the parallel result, shown in the lower panel of the table. Evidently, one cannot easily discriminate across specifications of the natural rates based on forecasting performance.

We now use the different natural rate estimates presented above to gauge the likely magnitude and persistence of natural rate misperceptions. We start by computing natural rate misperceptions solely due to the limitation that only observed data can be used in real time, assuming that the correct model for the natural rate is known. Given the problems of sampling and model uncertainty, we view these estimates as lower bounds on the true degree of uncertainty of natural rate estimates. The first column of the upper portion of Table 3 reports the sample standard deviations of the difference between the two-sided and one-sided estimates of the natural rate of unemployment $\left(u^{*}-\hat{u}^{*}\right)$ for the various estimation methods. This standard deviation ranges from about 0.5 to 0.8 percentage point, with the Kalman filter lying in the center at 0.66 percentage point. The lower parnel of the table reports the corresponding results for estimates of the natural rate of interest. The standard deviations in this case range from 0.9 to 1.7 percentage point, with the Kalman filter at 1.44 percentage point. In our subsequent analysis, we use the estimates from our multivariate Kalman filter

\footnotetext{
${ }^{10}$ However, the suggested forecast improvement from including the unemployment gap is based on withinsample performance. The usefulness of unemployment or output gap estimates for out-of-sample forecasts of inflation is much less clear (Stock and Watson, 1999; Orphanides and van Norden, 2001.)
} 
method as a baseline measure of the uncertainty regarding real-time perceptions of the natural rates of interest and unemployment in the historical data.

Natural rate misperceptions are highly persistent. The persistence of these series can be characterized with the first order autoregressive processes:

$$
\begin{gathered}
\left(u_{t}^{*}-\hat{u}_{t}^{*}\right)=\rho_{u}\left(u_{t-1}^{*}-\hat{u}_{t-1}^{*}\right)+\nu_{u, t}, \\
\left(r_{t}^{*}-\hat{r}_{t}^{*}\right)=\rho_{r}\left(r_{t-1}^{*}-\hat{r}_{t-1}^{*}\right)+\nu_{r, t},
\end{gathered}
$$

where the errors $\nu_{u, t}$ and $\nu_{r, t}$ are independent over time but may be correlated with each other and with other shocks realized during period $t$, including, importantly, the unobserved errors of the underlying processes for the natural rates, $\eta_{u, t}$ and $\eta_{r, t}$. Table 3 also presents least squares estimates of $\rho$ and $\sigma_{\nu}$ for the various misperceptions measures. In all cases, misperceptions are highly persistent, with the Kalman filter lying in the middle of the range on this dimension also. Note that the persistence in misperceptions does not necessarily imply any sort of inefficiency in the real-time estimates, but merely reflects the nature of these filtering problems.

We now extend our analysis of the mismeasurement problem to include model uncertainty. For this purpose we compare the one-sided estimate using each method to each of the two-sided estimates. For our set of six methods, this yields thirty-six measures of misperceptions for the natural rates of unemployment and interest. Table 4 summarizes the frequency distribution of the standard deviations and persistence from these alternative estimates of misperceptions. Both the standard deviations and the persistence measure of our baseline (Kalman filter) estimates for both natural rates, from Table 3, are close to the 25 th percentile as shown in Table 4 . Table 4 indicates generally larger and much more persistent misperceptions than those based on comparing the one- and two-sided estimates from a single model; indeed, the magnitude of misperceptions can be as much as twice that implied by the Kalman filter model. Moreover, these calculations do not reflect sampling uncertainty. In summary, combining the three forms of natural rate uncertainty suggests that conventional estimates of misperceptions based on comparing one-sided and two-sided estimates using a single estimation method are overly optimistic about the magnitude and persistence of the problem faced by policymakers. 


\section{A Simple Estimated Model of the U.S. Economy}

We evaluate monetary policy rules using a simple rational expectations model, the core of which consists of the following two equations:

$$
\begin{gathered}
\pi_{t}=\phi_{\pi} \pi_{t+1}^{e}+\left(1-\phi_{\pi}\right) \pi_{t-1}+\alpha_{\pi} \tilde{u}_{t}^{e}+e_{\pi, t}, \quad e_{\pi} \sim \operatorname{iid}\left(0, \sigma_{e_{\pi}}^{2}\right), \\
\tilde{u}_{t}=\phi_{u} \tilde{u}_{t+1}^{e}+\chi_{1} \tilde{u}_{t-1}+\chi_{2} \tilde{u}_{t-2}+\alpha_{u} \tilde{r}_{t-1}^{a}+e_{u, t}, \quad e_{u} \sim \operatorname{iid}\left(0, \sigma_{e_{u}}^{2}\right) .
\end{gathered}
$$

Here we use $\tilde{u}$ to denote the unemployment gap and $\tilde{r}^{a}$ to denote the real interest rate gap based on a one-year bill. This model combines forward-looking elements of the New Synthesis model studied by Goodfriend and King (1997), Rotemberg and Woodford (1999), Clarida, Gali and Gertler (1999), and McCallum and Nelson (1999), with intrinsic inflation and unemployment inertia as in Fuhrer and Moore (1995a), Batini and Haldane (1999), and Smets (2000). Given, the uncertainty regarding the proper specification of inflation and unemployment dynamics, later in the paper we also consider alternative specifications, including one with no intrinsic inflation and one with adaptive expectations.ause of its superior fit of the data.

The "Phillips curve" in this model (equation 8) relates inflation (measured as the annualized percent change in the GDP price index) during quarter $t$ to lagged inflation, expected future inflation, and expectations of the unemployment gap during the quarter, using retrospective estimates of the natural rate discussed below. The estimated parameter $\phi_{\pi}$ measures the importance of expected inflation on the determination of inflation. The unemployment equation (equation 9) relates the unemployment gap during quarter $t$ to the expected future unemployment gap, two lags of the unemployment gap, and the lagged real interest rate gap. Here two elements importantly reflect forward-looking behavior. The first element is the estimated parameter $\phi_{u}$, which measures the importance of expected unemployment, and the second is the duration of the real interest rate, which serves as a summary of the influence of interest rates of various maturities on economic activity. Because data on long-run inflation expectations are lacking, we limit the duration of the real rate to one year.

In estimating this model we are confronted with the difficulty that expected inflation and unemployment are not directly observed. Instrumental variable and full-information maximum likelihood methods impose the restriction that the behavior of monetary policy 
and the formation of expectations be constant over time, neither of which appears tenable over the sample period that we consider (1969-2002). Instead, we follow the approach of Roberts $(1997,2001)$ and Rudebusch (2002) and use the median values of the Survey of Professional Forecasters as proxies for expectations. We use the forecast from the previous quarter; that is, we assume expectations are based on information available at time $t-1$. To match the inflation and unemployment data as best as possible with the forecasts, we use first announced estimates of these series. ${ }^{11}$ Our primary sources for these data are the Real-Time Dataset for Macroeconomists and the Survey of Professional Forecasters, both currently maintained by the Federal Reserve Bank of Philadelphia (Zarnowitz and Braun (1993), Croushore (1993) and Croushore and Stark (2001)). Using the least squares method, we obtain the following estimates over the sample 1969:1 to 2002:2 (this choice of sample reflects the availability of the Survey of Professional Forecasters data):

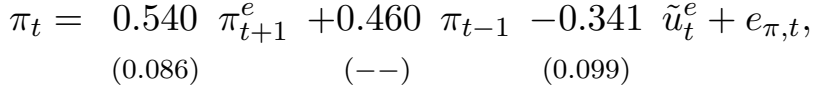

$$
\begin{aligned}
& S E R=1.38, D W=2.09, \\
& \tilde{u}_{t}=0.257 \tilde{u}_{t+1}^{e}+1.170 \tilde{u}_{t-1}-0.459 \tilde{u}_{t-2}++0.043 \tilde{r}_{t-1}^{a}+e_{u, t}, \\
& \begin{array}{llll}
(0.084) & (0.107) & (0.071) & (0.013)
\end{array} \\
& S E R=0.30, D W=2.08,
\end{aligned}
$$

In these results the numbers in parentheses are the estimated standard errors of the corresponding regression coefficients. The estimated unemployment equation also includes a constant term (not reported) that captures the average premium of the one-year Treasury bill rate we use for estimation over the average of the federal funds rate, which corresponds to the natural rate of interest estimates we employ in the model. In the model simulations we impose the expectations theory of the term structure whereby the one-year rate equals the expected average of the federal funds rate over four quarters.

In addition to the equations for inflation and the unemployment rate, we need to model the processes that generate both the true values for the natural rate of unemployment and interest and policymakers' real-time estimates of these rates. For this purpose we use our Kalman filter estimates as a baseline for the specification of the natural rate processes.

\footnotetext{
${ }^{11}$ Romer and Romer (2000) follow a similar procedure when comparing Federal Reserve Board Greenbook forecasts to the data.
} 
Throughout the remainder of the paper, we assume that the true values for the natural rates are given by the two-sided retrospective Kalman filter estimates. Specifically, we append the basic macroeconomic model to include equations (4) and (5) for $u^{*}$ and $r^{*}$, respectively, and compute the equation residuals - the "shocks" to the true natural rates - using the two-sided Kalman filter estimates.

For the policymakers' estimates of natural rates, we assume the difference between the true and estimated values follows an $\mathrm{AR}(1)$ process described by equations (6) and (7), with the $\operatorname{AR}(1)$ set equal to that based on the regression using the difference between the one- and two-sided Kalman filter estimates reported in Table 3. As seen in that table, this specification approximates several common filtering methods. The residuals from these equations represent the shocks to mismeasurement under the assumption that the policymaker possesses the correctly specified Kalman filter models.

Because we are interested in the possibility that the policymakers' natural rate estimates result from a misspecified model, we allow for a range of estimates of the magnitude of natural rate mismeasurement, indexed by $s$, in our policy experiments. The case of $s=0$ corresponds to the "best case" benchmark (a standard assumption in the policy rule literature), in which the policymaker is assumed to observe the true value of both natural rates in real time. For this case, we set the residuals of the two mismeasurement equations to zero. The case of $s=1$ corresponds to the assumption that the policymaker possesses the correctly-specified Kalman filter models (including knowledge of all model parameters). In this case, the residuals from the mismeasurement equation are set to their historical values. As discussed above, owing to the possibility of model misspecification, this calculation most likely yields a conservative figure for the magnitude of real-world natural rate misperceptions. To approximate the policymakers' use of a misspecified model of natural rates, we examine simulations where we amplify the magnitude of misperceptions by multiplying the residuals to the mismeasurement equations by $s$. As indicated by the results in Table 4, incorporating model misspecification can yield differences between one- and two-sided on average twice as large as those implied by comparing the one- and two-sided Kalman filter estimates, implying a value of $s$ of up to $2 .{ }^{12}$ In addition, these calculations ignore sampling

\footnotetext{
${ }^{12}$ For example, $s=2$ approximately corresponds to the case of a policymaker who may incorrectly rely on the HP filter (with $\lambda=1600$ ) for real-time estimates of the natural rates when the true process continues to be described by our two-sided Kalman filter. In terms of the policy evaluations we report later on, we
} 
uncertainty associated with estimated models; in consideration of this source of uncertainty, we also consider the case of $s=3$.

For a given value of $s$, we estimate the variance-covariance of the six model equation innovations (corresponding to equations 4-7, 10, and 11) using the historical equation residuals, where the misperception residuals are multiplied by $s$, as described above. Note that, by estimating the variance-covariance matrix in this way, we preserve the correlations among shocks to inflation, the unemployment rate, changes in the natural rates, and natural rate misperceptions present in the data. For example, shocks to misperceptions of $r^{*}$ are positively correlated with shocks to the unemployment rate and to $u^{*}$ misperceptions, and shocks to $u^{*}$ misperceptions are negatively correlated with shocks to inflation.

For a given monetary policy rule of the form of equation (1), we solve for the unique stable rational expectations solution, if one exists, using the Anderson and Moore (1985) implementation of the Blanchard and Kahn (1980) method. ${ }^{13}$ Given the model solution and the variance-covariance matrix of equation innovations, we then numerically compute the unconditional moments of the model. This method of computing unconditional moments is equivalent to, but computationally more efficient than, computing them from stochastic simulations of extremely long length (see Levin, Wieland, and Williams 1999 for a detailed discussion).

\section{$5 \quad$ Policy Rule Evaluation}

We now examine how uncertainty regarding the natural rates of interest and unemployment influences the design and performance of policy rules. We assume that the policymaker is interested in minimizing the loss, $\mathcal{L}$, equal to the weighted sum of the unconditional squared deviations of inflation from its target, those of the the unemployment rate from its true natural rate, and the change in the short-term interest rate:

$$
\mathcal{L}=\omega \operatorname{Var}\left(\pi-\pi^{*}\right)+(1-\omega) \operatorname{Var}\left(u-u^{*}\right)+\psi \operatorname{Var}(\Delta f) .
$$

confirmed that using $s=2$ with the Kalman filter errors are also very similar to those based on these mispecified errors. This suggests that our approach of summarizing the magnitude of misperceptions by a single parameter, $s$, captures the key implications of policymakers' misspecification of the natural rate process.

${ }^{13}$ We abstract from the complications arising from imperfections in the formation of expectations (Orphanides and Williams, 2002). For simplicity, we also abstract from errors in within-quarter observations of the rates of inflation and unemployment. 
As a benchmark for our analysis and for comparability with earlier policy evaluation work, we consider preferences equivalent to placing equal weights on the variability of inflation and the output gap. Assuming an Okun's law coefficient of 2, this weighting implies setting $\omega=0.2$. We include a relatively modest concern for interest rate stability, setting $\psi=0.05$ Later in the paper, we show that the main qualitative results are not sensitive to changes in $\omega$ and $\psi$. In all our experiments, we assume the policymaker has a fixed and known inflation target, $\pi^{*} .{ }^{14}$

We start our analysis of the effects of natural rate mismeasurement by examining macroeconomic performance under the classic and revised forms of the original Taylor rules:

$$
\begin{gathered}
f_{t}=\hat{r}_{t}^{*}+\pi_{t}+0.5\left(\pi_{t}-\pi^{*}\right)-1.0\left(u_{t}-\hat{u}_{t}^{*}\right) \quad(\text { the classic rule }), \\
\left.f_{t}=\hat{r}_{t}^{*}+\pi_{t}+0.5\left(\pi_{t}-\pi^{*}\right)-2.0\left(u_{t}-\hat{u}_{t}^{*}\right) \quad \text { (the revised rule }\right) .
\end{gathered}
$$

The direct effects of natural rate mismeasurement on the setting of policy are transparent under these rules: a 1-percentage-point error in $r^{*}$ translates into a one percentage point error in the interest rate, while a 1-percentage-point error in $u^{*}$ translates into a -1-percentage-point error in the classic Taylor rule and a -2-percentage-point error for the revised rule. The first panel of Table 5 reports the standard deviations of the inflation rate, the unemployment rate gap, and the change in the federal funds rate, as well as the associated loss under the classic Taylor rule in our model, for values of $s$ between 0 and 3. The next panel does the same for the revised Taylor rule. Figure 5 illustrates some of these results graphically, tracing out the unconditional standard deviations of inflation (top panel) and the unemployment gap (bottom panel) for our model economy when policy is based on the classic Taylor rule or the revised Taylor rule for different values of $s$.

Starting with the case of no misperceptions, $s=0$, we see that both the classic and revised Taylor rules are effective at stabilizing inflation and the unemployment rate gap. The revised variant of the rule is more responsive to the perceived degree of slack in labor markets and thereby achieves lower variability of both inflation and the unemployment gap, at the cost of modestly higher variability of the change in the interest rate. This result is consistent with the findings reported in the studies collected in Taylor (1999a) and

\footnotetext{
${ }^{14} \mathrm{We}$ assume that the inflation target is sufficiently above zero to minimize issues related to the zero bound on interest rates and other nonlinearities associated with very low inflation or deflation (Akerlof, Dickens and Perry, 1996; Orphanides and Wieland, 1998; Reifschneider and Williams, 2000).
} 
elsewhere. However, policy outcomes for both rules deteriorate markedly and increasingly so as the degree of misperceptions regarding the natural rates increases. For example, under the classic Taylor rule, the standard deviation of inflation is 2.14 when $s$ is assumed to be 0 , but increases to 3.67 under the assumption that $s=1$. In addition, and of greater interest from a policy design perspective, Figure 5 illustrates that the performance deterioration owing to natural rate uncertainty is worse for the revised Taylor rule, because it places greater emphasis on the unemployment gap. Indeed, for even modest levels of natural rate misperceptions, the classic Taylor rule performs better than the revised version, a result consistent with findings based on output gap mismeasurement in Orphanides (2000b).

We now examine the efficient choices for the two parameters, $\theta_{\pi}$ and $\theta_{u}$, that measure the responses to the inflation and unemployment gaps, respectively, in a policy rule of the same functional form as the Taylor rule with natural rate uncertainty. In this exercise, we assume that the policymaker is interested in identifying a simple fixed policy rule that can provide guidance for minimizing the weighted variances in the loss function (12) with the weights described above. Figure 6 presents the optimal choices of the two parameters for various values of $s$. As the left-hand panel shows, the optimal responsiveness to inflation increases with uncertainty in this case. From the right-hand panel it is also evident that the optimal response to the unemployment gap drops (in absolute value) and approaches zero as the degree of mismeasurement increases to values of $s$ beyond 2. This finding confirms the parallel result, reported by Orphanides (1998), Smets (1998), Rudebusch (2001, 2002), McCallum (2001), and Ehrmann and Smets (2002), of attenuated responses to the output gap as an efficient response to uncertainty regarding the measurement of the output gap in level rules.

This attenuation result contrasts with standard applications of the principle of certainty equivalence whereby, under certain conditions, the policymaker could compute the optimal policy abstracting from uncertainty and apply the resulting optimal rule by substituting into it, for the unobserved values, estimates of the natural rates based on an optimal filter (Swanson (2000) and Svensson and Woodford (2002) offer recent expositions on this issue.) Rather, our result is similar to Brainard's (1967) conservatism principle, where attenuation is shown to be optimal when policy effectiveness is uncertain.

Two key conditions that are necessary for the standard application of certainty equiv- 
alence are violated in our analysis. First, we focus on "simple" policy rules that respond to only a subset of the relevant state variables of the system, and certainty equivalence only applies to fully optimal rules. The distinction is especially important in the presence of concern about model misspecification. As discussed by Levin, Wieland, and Williams (1999, 2002), simple rules appear to be more robust to general forms of model uncertainty than rules optimized to a specific model, arguing that in the broader context of the types of uncertainty that policymakers face, an exclusive focus on fully optimal rules may be misguided. Second, and especially relevant for our analysis, the traditional applications of certainty equivalence rely on the existence of a model that is presumed to be true and known with certainty, and which policymakers can apply to obtain "optimally" filtered estimates of the natural rates. In light of the uncertainty about how to best model and estimate the natural rate processes discussed earlier, we find this assumption untenable. ${ }^{15}$

We now assess the implications of ignorance regarding the precise degree of uncertainty policymakers may face about the natural rates. We start by examining the costs of basing policy decisions on rules that are optimized with incorrect baseline estimates of this uncertainty. We examine the performance of rules optimized for natural rate mismeasurement of degree $s=0$ and $s=1$ when the true extent of mismeasurement may be different. The economic outcomes associated with this experiment are shown in Figure 7 and the third panel of Table 5, for true values of $s$ ranging from 0 to 3 . As seen in the figure, the rule optimized on the assumption of no misperceptions performs poorly even at the baseline value of $s=1$, whereas the rule optimized assuming $s=1$ is much more robust to natural rate mismeasurement.

\footnotetext{
${ }^{15}$ To gain some insight into the breakdown of the traditional certainty equivalence results in the presence of filter uncertainty, consider the simple static problem of minimizing the expected squared value of variable $y=x-c$, where $x$ is a random variable and $c$ is the policy control. If $x$ is observed, then the solution is trivial: set $c=x$. Suppose, instead, that $x$ is not directly observable but instead must be inferred from the variable $z=\xi x+\eta$. Let $x$ and $\eta$ be zero mean independently and normally distributed random variables with constant and known variances $\sigma_{x}^{2}$ and $\sigma_{\eta}^{2}=\bar{\sigma}_{\eta}^{2}$, respectively, and without loss of generality let $\xi=1$. Then, if all these parameters are known, certainty equivalence applies and the optimal control is $c=\hat{x}=\kappa z$, where $\kappa=\frac{\sigma_{x}^{2}}{\sigma_{x}^{2}+\bar{\sigma}_{\eta}^{2}}$ is the optimal filter applied to $z$. Next, to illustrate filter uncertainty, suppose that instead of being fixed and known, $\sigma_{\eta}$ and $\xi$ are independently drawn with equal probabilities from $\left\{\bar{\sigma}_{\eta}-s_{\eta}, \bar{\sigma}_{\eta}+s_{\eta}\right\}$, and $\left\{1-s_{\xi}, 1+s_{\xi}\right\}$, respectively. In this case, if we consider the optimal linear policy $c=\theta z$, the optimal choice of $\theta$ is given by:

$$
\theta=\frac{\sigma_{x}^{2}}{\left(1+s_{\xi}^{2}\right) \sigma_{x}^{2}+\left(\bar{\sigma}_{\eta}^{2}+s_{\eta}^{2}\right)} .
$$

Note that $\theta=\kappa$ for $s_{\xi}=s_{\eta}=0$ but is strictly decreasing in both $s_{\xi}$ and $s_{\eta}$. Thus, the optimal linear policy attenuates the response relative to that implied assuming certain and known $\sigma_{\eta}$ and $\xi$.
} 
These experiments point to an asymmetry in the costs associated with natural rate mismeasurement: the cost of underestimating the extent of misperceptions significantly exceeding the cost of overestimating it. Policy rules optimized under the false presumption that misperceptions regarding the natural rates are likely to be small are characterized by large responses to the unemployment gap. This can prove extremely costly. By comparison, policies incorrectly based on the presumption that misperceptions regarding natural rates are likely to be large are more timid in their response to the unemployment gap, but this is associated with relatively little inefficiency. In the case where there are in fact no misperceptions, the policy optimized under the assumption of $s=1$ delivers modestly worse results than the policy optimized under the assumption of no misperceptions; however, in the presence of even a modest degree of misperception, the performance of the policy designed on the assumption of no misperceptions deteriorates dramatically as the degree of mismeasurement increases.

Given the potential difficulties associated with the optimized Taylor rules in the presence of natural rate mismeasurement, it is of interest to compare the performance of these rules to our alternative family of "robust" difference rules of the form given by equation (3). In the present context, this class of rules is robust to natural rate mismeasurement because natural rate estimates do not enter into the implied policy setting decision. The final row of Table 5 presents the efficient choice of the parameters $\theta_{\pi}$ and $\theta_{\Delta u}$ corresponding to this robust rule chosen to minimize the same loss as the optimized Taylor rules. The stabilization performance of this rule is also shown in Figure 7. In this model this rule performs about as well as the Taylor rules (1) when the natural rates are assumed known, and, consequently, dominates these rules in the presence of uncertainty, since with greater uncertainty about misperceptions regarding the natural rates, the performance of the Taylor rules deteriorates, whereas the performance of the robust rule remains unchanged. The key reason that the robust difference rule performs so well relative to the Taylor-type rules even absent natural rate uncertainty is that it naturally incorporates a great deal of policy inertia. As noted above, this is an important ingredient of successful policies in forward-looking macro models when policymakers are concerned about interest rate variability.

Given these results, we now consider a more flexible form of policy rule that combines level and first-difference features. Figure 8 presents the optimized parameters corresponding 
to the generalized policy rules given in equation (2) for different values of $s$, which is assumed to be known by the policymaker. If the natural rates of interest and unemployment are assumed to be known, then the efficient policy rule exhibits partial adjustment and a strong response to the unemployment gap, along with a response to inflation and the change in the unemployment rate. We now examine how the optimal policy responses are altered when the degree of mismeasurement is increased and this is known by the policymaker. First, the response to the unemployment gap diminishes sharply and approaches zero as the degree of uncertainty increases. Second, compensating for the reduced response to the unemployment gap, in the face of increased uncertainty the efficient rules call for larger responses to changes in the rate of unemployment. Third, the degree of inertia in the efficient rules increases as the degree of uncertainty rises, approaching the limiting value $\theta_{f}=1$. In the limit as the degree of uncertainty increases, the generalized rule collapses to the robust difference rule.

The performance of optimized generalized rules is shown in Figure 9, which repeats the experiments reported in Figure 7 but using optimized generalized policy rules. As in the case of Taylor rules, the performance of the generalized rule optimized assuming no natural rate misperceptions deteriorates dramatically if natural rates are in fact mismeasured. In contrast, the rule optimized assuming $s=1$ is quite robust to natural rate mismeasurement. As noted, this rule features very modest responses to estimates of $r^{*}$ and $u^{*}$. The performance of the robust difference rule is invariant to the degree of mismeasurement and exceeds that of the generalized rule optimized assuming $s=1$ for all values of $s>1.5$.

The asymmetry in outcomes due to incorrect assessments, shown in Figure 9, suggests that, when policymakers do not possess a precise estimate of the magnitude of misperceptions regarding the natural rates, it may be advisable to act as if the uncertainty they face is greater than their baseline estimates. We examine this issue in greater detail with an example shown in Figure 10. To facilitate comparisons, the figure plots pairs of the policy responses, $\theta_{u}$ and $\theta_{f}$, corresponding to different values of a known degree of uncertainty (from Figure 8). Note in particular the location of the efficient policies corresponding to $s=0,1$, and 2 and the limiting case of difference rules ("Robust policy" in the figure).

Consider the following problem of Bayesian uncertainty regarding $s$. Suppose that the policymaker has a diffuse prior with support $[0,2]$ regarding the likely value of $s$. By construction, the baseline estimate of uncertainty is thus $s=1$. As the figure shows, however, 
the efficient choice based on the optimization with the diffuse prior over $s$, corresponds to a choice of $\theta_{u}$ and $\theta_{f}$ that is closer to the certain efficient choice with value $s=2$, the worse outcome for this distribution. In this sense a policymaker with a Bayesian prior over the likely degree of uncertainty he may face about the natural rates should act as if he were confident that the degree of uncertainty he faces is greater than his baseline estimates. Of course, complete ignorance regarding the distribution of $s$ leads to the robust control solution, which here corresponds to the limiting case of the robust difference rule given by equation (3).

The precise parameterization of the robust difference rule for our model depends on the loss function parameters, $\omega$ and $\psi$. As noted earlier, in our analysis thus far we set $\omega=.2$, and $\psi=0.05$ which can be interpreted as a "balanced" preference for output and inflation stability but exhibits relatively low concern for interest variability. For comparison, in Table 6, we present alternative robust rules corresponding to different values of the loss function parameters: $0.1,0.2$, and 0.5 for $\omega$ and $0.05,0.5$ and 5.0 for $\psi$. Given $\psi$, higher values for $\omega$ correspond to a larger inflation response coefficient, $\theta_{\pi}$, with a relatively small effect on $\theta_{\Delta u}$. Given $\omega$, a greater concern for interest rate smoothing reduces both response coefficients, $\theta_{\pi}$ and $\theta_{\Delta u}$. This leads to a noticeable reduction in the standard deviation of interest rate changes, but at the cost of higher variability in both inflation and the unemployment gap.

\section{Robustness in Alternative Models}

Thus far our analysis has been conditioned on the assumption that the baseline model we estimated in section 4 offers a reasonable characterization of the workings of the economy in our sample, including, importantly, the role of expectations. This assumption may be critical for interpreting our policy evaluation analysis and finding that the simple difference policy rule we identify offers a useful and robust benchmark for policy analysis. Given that researchers and policymakers may hold different views about the most appropriate model for characterizing the role of expectations, and given the uncertainty associated with any estimated model, it is of interest to examine whether the basic insight regarding the robustness of difference rules in the face of unknown natural rates holds in alternative models. To that end we also examined two alternative models based on the same historical data as 
our baseline model but reflecting quite different views regarding the role for expectations: a new synthesis model in which economic outcomes depend much more critically on expectations than in our baseline model, and an accelerationist model in which the role of rational expectations is largely assumed away.

\subsection{A New Synthesis Model}

In the new synthesis model we examine, no lagged terms of inflation and unemployment appear in equations (8) and (9), the short-term interest gap enters the unemployment equation, and there is no lag in the information structure regarding expectations (that is, we assume time $t$ expectations):

$$
\begin{gathered}
\pi_{t}=\pi_{t+1 \mid t}^{e}+\alpha_{\pi} \tilde{u}_{t \mid t}^{e}+e_{\pi, t}, \\
\tilde{u}_{t}=\tilde{u}_{t+1 \mid t}^{e}+\alpha_{u} \tilde{r}_{t}+e_{u, t} .
\end{gathered}
$$

We calibrated this model to the 1969-2002 sample so that the characteristics of the underlying data are the same as in our baseline model. As is well known, this specification does not capture the dynamic behavior of the inflation and unemployment (or output gap) data very well when the shocks to the inflation and unemployment equations, $e_{\pi}$ and $e_{u}$ are serially uncorrelated (Estrella and Fuhrer, 2002). Following Rotemberg and Woodford (1999), McCallum (2001) and others, we therefore allow the errors $e_{\pi}$ and $e_{u}$ to be serially correlated and estimated the model with this modification using the same data as in our baseline model, with the changes noted above. Because our unrestricted least squares estimate of $\alpha_{u}$ was essentially zero, and therefore inconsistent with the theoretical foundations of this model, we imposed a value for that parameter. We set $\alpha_{u}=0.05$, following with the theoretically motivated calibration presented in McCallum (2001) based on a model of the output gap (see Nelson and Nikolov (2002) for further discussion). The resulting estimated form of this model is

$$
\begin{gathered}
\pi_{t}=\pi_{t+1 \mid t}^{e}+\underset{(0.103)}{-0.408} \tilde{u}_{t \mid t}^{e}+e_{\pi, t} \\
\rho_{e, \pi}=0.26, S E R=1.33, D W=2.04 \\
\tilde{u}_{t}=\tilde{u}_{t+1 \mid t}^{e}+0.05 \tilde{r}_{t}+e_{u, t} \\
\rho_{e, u}=0.72, S E R=0.21, D W=2.23 .
\end{gathered}
$$


Using these estimates and the associated covariance structure of the errors in this model, we computed efficient policy responses for the generalized rule given by equation (2) without and with uncertainty regarding the natural rates as with our baseline model. An interesting feature of the new synthesis model that differs from our baseline model is that, in the absence of uncertainty about the natural rates, the efficient policies are super-inertial, that is $\theta_{f}>1$. (This is explored in detail by Rotemberg and Woodford (1999).) In the presence of uncertainty, of course, such policies also introduce policy errors from misperceptions about the natural rate of interest similar to policies with $\theta_{f}<1$. The only difference is that the sign of the error is reversed. Figure 11, which repeats for this model the experiments shown in Figure 8 for our baseline model, confirms that, in the presence of increasingly higher uncertainty regarding the real-time estimates of the natural rate, the efficient policy again converges towards $\theta_{f} \rightarrow 1$ and $\theta_{u} \rightarrow 0$. Evidently, the difference rule of the form given by equation (3) represents the robust policy for dealing with natural rate uncertainty in this model as well as in the baseline model. This can also be confirmed in Table 7, which compares the values of the loss function corresponding to the robust rule given by equation (3) and the generalized rule given by equation (2) optimized for $s=0$. From the second row of the table it is evident that the cost of adopting the robust rule relative to the optimized one is modest when $s=0$, and the benefits considerable if the true level of uncertainty is $s=1$ or higher. This is similar to the result indicated earlier for our baseline model, as shown in the first row of the table.

\subsection{An Accelerationist Model}

A key feature of the baseline and new synthesis models is the assumption of rational expectations. As noted above, difference rules perform reasonably well in those models even in the absence of natural rate misperceptions. In "backward-looking" models with adaptive expectations, however, difference rules generally perform very poorly and may be destabilizing because of the instrument instability problem. Moreover, in such models the costs associated with responding to the change in the output gap or the unemployment rate, as opposed to the levels of the gaps, tend to much greater than in forward-looking models with rational expectations. To explore the sensitivity of policy to a different specification of expectations, we estimate a backward-looking model that imposes an accelerationist Phillips 
curve and assumes that rational expectations are unimportant for determining aggregate demand, with the exception of the determination of the real interest rate, where we retain the ex ante real rate of interest from our baseline model:

$$
\begin{aligned}
& \Delta \pi_{t}=+0.477 \pi_{t-1}+0.099 \pi_{t-2}+0.255 \pi_{t-3}+0.123 \pi_{t-4} \\
& \begin{array}{llll}
(0.089) & (0.094) & (0.093) & (0.088)
\end{array} \\
& -0.278 \tilde{u}_{t-1}-1.189\left(u_{t-1}-u_{t-2}\right)+e_{\pi, t} \\
& (0.096) \quad(0.323) \\
& S E R=1.36, D W=1.96
\end{aligned}
$$

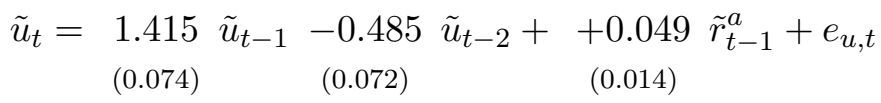

$$
\begin{aligned}
& S E R=0.31, D W=2.14
\end{aligned}
$$

Figure 12, which parallels Figures 8 and 11 for our baseline and new-synthesis models, respectively, presents the simulated efficient response coefficients of the generalized rule in equation (2) for this model. Two findings are apparent. As in the baseline and new synthesis models, uncertainty regarding the natural rates raises the efficient degree of inertia in the policy rule and leads to a significant attenuation of the policy response to the unemployment gap. However, the efficient policy for this model does not converge to the robust difference rule given by equation (3) as quickly as in the other two models. Evidently, in a backward-looking world, there are costs from completely ignoring the estimated levels of the unemployment gap and the natural rate of interest, even when the uncertainty regarding natural rates is significant. The last row of Table 7 confirms this result. However, even in this model our experiments suggest that policies should exhibit significant smoothing and attenuated responses to the unemployment gap.

As the last row in also Table 7 indicates, even in this case the robust rule for this model performs better than the rule optimized under the assumption of no misperceptions when the true degree of misperceptions is as high as $s=3$. However, this is a much higher threshold than that for our baseline and new synthesis models.

\subsection{Robustness to Both Model and Natural Rate Uncertainty}

McCallum (1988) and Taylor (1999b) argue that monetary policy should be designed to perform across a wide range of reasonable models. In this section, we follow Levin, Wieland, 
and Williams (2002) and compute the optimized policy rule given priors over the three models discussed above. For this experiment we assign equal weights to the three models and compute the optimal choice of parameters for the robust policy rule. The results of this exercise are reported in Table 8, which follows a format similar to that of Table 6, which was based on the baseline model alone. The third and fourth columns show the optimal rule parameters for the objective of minimizing the sum of the losses in the three models. The last three columns show the corresponding losses. Comparison of the two tables reveals that the optimal rule allowing for model uncertainty features slightly larger responses to the change in the unemployment rate, but the response to the inflation rate is from 3 to 5 times larger than in the baseline model. Although not shown in the table, the parameters of the generalized rule that accounts for model uncertainty lie between those of the baseline and accelerationist models.

\section{Misperceptions and Historical Policy Outcomes}

Our policy evaluation experiments highlight that overconfidence regarding the policymaker's ability to detect changes in the natural rates - that is, the pursuit of policies that are "optimal" under the false assumption that misperceptions regarding real-time assessments of the natural rates are smaller than they actually are - can have potentially disastrous consequences for economic stability. The sensitivity of economic outcomes to policy design is potentially informative for understanding the historical performance of monetary policy, especially during episodes when natural rates changed significantly and real-time assessments of these rates were likely subject to substantial misperceptions. As an illustration, we perform two experiments comparing outcomes from the Taylor, optimized, and robust rules, designed to highlight some elements we find important for understanding the stagflationary experience of the 1970s and the disinflationary boom of the 1990s.

\subsection{The 1970s}

The stagflationary experience of the 1970s has proven a rich laboratory for understanding potential pitfalls in policy design. A number of plausible explanations that boil down to inherently "bad" policy have already been put forward for the dismal outcomes of that period: possible confusion of real and nominal interest rates, insufficient responsiveness 
of policy to inflation, attempted exploitation of a Phillips curve that was misspecified to include a with a stable long-run tradeoff between inflation and unemployment, and so forth. In our illustration we instead highlight the more subtle complication arising from comparing policies that, as already pointed out, would appear to be "good" under certain circumstances, but have different degrees of sensitivity to the presence of misperceptions regarding the natural rates.

To set the stage, consider first the evolution of perceptions regarding the natural rates of interest and unemployment following unanticipated increases in the natural rates such as appear to have been an integral part of the 1970s experience. (We review some direct evidence from the historical record on the evolution of beliefs below.) To illustrate the misperceptions that we wish to consider for this experiment, Figure 13 traces an example that assumes that both natural rates increase over a period of $2-1 / 2$ years by 1.5 percentage points. We assume that, at the beginning of the simulation, before the unexpected increases, policymakers know the correct levels of the natural rates. Despite starting with correct estimates, their gradual learning of the evolution of the natural rates when they unexpectedly rise results in temporary but nonetheless persistent misperceptions. Given the average speed of learning implied by our baseline estimates of historical misperceptions in our sample, the 1.5 percentage increase shown by the solid lines in Figure 13 results in real-time estimates shown by the dashed lines. For both natural rates, errors in real-time estimates - the difference between the true natural rate and the real-time estimates - gradually increase at first, to about 1 percentage point, and then dissipate slowly over a period of many years.

The effect of these misperceptions on economic outcomes for the classic and revised Taylor rules are compared in Figure 14. The upper panel shows that, when policy follows the classic Taylor rule, natural rate misperceptions lead to a persistent rise in inflation, whcih peaks at 3 percentage points above the policymaker's objective. The bulk of this unfavorable outcome is due to the strong response of this policy rule to an incorrectly estimated unemployment gap, which can be seen in the lower panel. As the policymaker's perceptions of the natural rate lag behind reality, the policymaker incorrectly and strongly attempts to stabilize the rate of unemployment at a level that is persistently too low. Throughout the simulation, the policymaker believes that the actual unemployment rate is above the natural rate, and policy actions impede the movement of the economy towards 
the true natural rate. The outcome is the modest stagflationary experience shown in the figure. The magnitude of the increase in inflation is greater for the Revised Taylor Rule because this rule is more responsive to the size of the perceived unemployment rate gap.

The magnitude of the peak inflationary effect depends on the parameters of the policy rule, but as long as policy responds to natural rates, the effects are quite persistent. The top two panels of Figure 15 show the responses from the generalized rule optimized under the assumption of no misperceptions. The peak rise in the inflation rate is nearly 7 percentage points and even after seven years inflation is nearly 3 percentage points above target. The robust policy cannot avoid the initial increase in unemployment and inflation either, as seen in the bottom two panels of the figure. However, because the robust policy is not guided by perceptions of the unemployment gap, but only by the evolution of inflation and changes in the unemployment rate, policy does not impede the movement of the economy towards the true natural rate in the way the optimized policy does. Consequently, the increase in the natural rates leads to a much less persistent deviation of inflation from its target in this case (bottom left-hand panel).

The relevance of this comparison for explaining the events of the 1970s rests on two elements. The first is that the misperceptions regarding the natural rate of unemployment, and to a lesser degree the natural rate of interest, significantly influenced policy. Second, and perhaps more controversial element is that policymakers at the time actually operated in a way resembling the Taylor rule or our "optimal" policy approach, instead of a more robust policy.

Bearing on this are the fascinating intellectual debates regarding "activist" countercyclical stabilization policies and the observation that proponents of such policies appeared to have won the day at the turn of the 1970s. (See Orphanides, 2000a,b for a historical review.) The perceived triumph of activist stabilization policy is reflected in many writings, including those of Heller (1966) and Okun (1970), and appeared to capture the hopes of both academic economists and policymakers across a wide spectrum of ideologies and backgrounds. One succinct accounting of the policy errors committed using this lens was offered by Stein (1984) who reflected on policymakers' attempts to guide the economy to its "optimum feasible path" (p. 171) at the turn of the 1970s by targeting "the natural rate of unemployment' which we thought to be 4 percent" (p. 19). In contrast, our baseline 
estimates, as well as those by the Congressional Budget Office, suggest that the natural rate of unemployment at the beginning of the 1970s was nearly 6 percent. Stein's account is corroborated by the recent retrospective on Paul McCracken's service at the Council of Economic Advisers (Jones 2000). The view from the Federal Reserve suggests a similar picture. Shortly after he left the Federal Reserve Board, Arthur Burns (1979), who had served as Chairman from 1970 to 1978, expressed his anguish over the the deleterious effects of underestimating the natural rate of unemployment; like Stein, he noted that the initial estimate of 4 percent proved, retrospectively, to have been too low. As Orphanides (2000a,b) documents, the related estimates of potential output and the output gap during the early 1970s proved, retrospectively, to have been exceedingly high.

Many issues complicated the measurement of the natural rate of unemployment in the early 1970s, including disagreements regarding modelling inflation dynamics and the Phillips curve, the meaning of "full employment," the proper accounting of demographics, modelling expectations and so forth. Starting with the first volume in 1970, the first few years of the Brookings Papers on Economic Activity provide a valuable source documenting the debate and evolution of views regarding the natural rate of unemployment. Indeed, in the very first meeting of the Brookings panel, Okun and Teeters (1970) presented an analysis of the "full employment" surplus assuming that the appropriate definition for "full employment" was the widely accepted during the previous decade 4 percent rate. Hall (1970) identified the "equilibrium level of unemployment" or "full employment unemployment" as the level that, "...if maintained permanently, would produce a steady rate of inflation of 3 or 4 percent per year," (p. 370) and noted that "[m]ost economists agree that this is somewhere between 4 and 5 percent unemployment." (p. 370). Perry (1970) presented estimates of the shifting Inflation-Unemployment tradeoff adjusting for changes in the demographic composition of the employment force (what later became known as "Perry weighting"), and the dispersion of unemployment among the age-sex groups of the labor force. According to his estimates (Figure 2, p. 432), whereas an unemployment rate of about 4 percent was consistent with a 3 percent annual increase in the consumer price index during the mid-1950s, by 1970 the unemployment rate would have had to be around five percent to be consistent with the same 3 percent rate of inflation. Finally, in one of the earliest exercises of policy design based on an estimated econometric model at the Federal Reserve (and,as far as we are 
aware, the earliest such exercise using a model consistent with the natural rate hypothesis), Poole (1971) presented experiments using the Federal Reserve's econometric model with two versions of a Phillips curve, the "standard model" (with a sloping "long-run" Phillips curve) and an "accelerationist model." Poole's simulations using the standard model showed that inflation could be stabilized below 3 percent with a 4 percent rate of unemployment. In simulations of the accelerationist model the implicit "natural" rate of unemployment was 4.5 percent. Already from this work from 1970 and 1971 it is clear that estimates of the natural rate were beginning to rise from the 4 percent view that had prevailed during the 1960s. Nonetheless, the evidence is compelling that misperceptions regarding the natural rate of unemployment were sizable at the turn of the 1970s.

Whereas such real-time estimates of the natural rate of unemployment are well documented, real-time estimates of the natural rate of interest are hard to come by. One source is the report prepared each year by the trustees of the Social Security system; for several decades this report has included projections of long-term interest rates. The forecast longrun real interest rate reported by the trustees rose from 2-1/2 percent in 1972 to $3-1 / 4$ percent in 1975. Before 1972 only nominal rates were projected, and estimates of this rate rose by a full percentage point between 1969 and 1972. Given the relatively modest rise in inflation during that period, this rise in nominal rates can be interpreted as a significant increase in long-run real rates. Overall, this evidence provides some support for a significant increase in the perceived natural rate of interest over this period.

\subsection{The 1990s}

What Blinder and Yellen (2001) have called the "fabulous decade" arguably constitutes, in some respects, an exact opposite of the dismal experience of the 1970s. During the 1990s the natural rate of unemployment apparently drifted downward, and significantly so. This lower level of the natural rate of unemployment went hand in hand with somewhat lower inflation; however, inflation more or less remained in line with policymaker descriptions of their price stability objectives.

One possible difference from the experience of the 1970s is that natural rate misperceptions may have been smaller and less persistent in the more recent episode. Ball and Tchaidze (2002), for example, argue that Federal Reserve's implicit NAIRU estimates may 
have fallen rapidly in the second half of the 1990s. Even so, the record indicates the possibility of significant misperceptions. The FOMC transcripts for 1994 and 1995, for example, indicate that some members of the Committee as well as Federal Reserve Board staff held the view that the natural rate of unemployment was around 6 percent at the time. By 2000, then Governor Meyer, indicated that a range of 5 to 5-1/4 percent was a better estimate (Meyer, 2000). This points towards a nontirivial misperception, perhaps as high as 1 percentage point, for the middle of the decade. ${ }^{16}$ Table 9 suggests similar revisions in responses from the Survey of Professional Forecasters as well as the estimates published by the he Congressional Budget Office and the Council of Economic Advisers.

An alternative possibility is that, despite significant misperceptions regarding the natural rate of unemployment, economic outcomes were better because monetary policy was more robust to such errors than the policy framework in place during the 1970s. To highlight this possibility, Figure 16 presents two alternative illustrations for this period, tracing the evolution of the economy following a reduction in the natural rate of unemployment under our optimized and robust policies. Here we assume that the natural rate of interest remains unchanged and that the change in the natural rate of unemployment has the the same size and timing as that shown in the right-hand panels of Figure 13, but opposite sign. Assuming the 1.5 percent reduction in the natural rate of unemployment underlying the simulation, policy under the optimized rule would have led to deflation over this period-with infation falling by almost 6 percentage points during the simulation and staying well below its initial value for many years. By contrast, our robust policy appears more successful in replicating the "Goldilocks"-like of economic outcomes of this period.

\section{Concluding Remarks}

This paper has critically reexamined the usefulness of the natural rates of interest and unemployment in the setting of monetary policy. Our results suggest that underestimating the unreliability of real-time estimates of the natural rates may lead to policies that are very very costly in terms of the stabilization performance of the economy. It is important to note that our critique does not necessarily imply any disagreement with the validity or usefulness

\footnotetext{
${ }^{16}$ Transcripts and other documents relating to FOMC meetings are released with a five-year lag and are therefore not yet available for years after 1996.
} 
of these concepts for understanding and describing historical macroeconomic relationships. Indeed, our analysis and conclusions are based entirely on models where deviations from natural rates are the primary drivers of inflation and unemployment. Instead, we argue that uncertainty about natural rates in real time recommends against excessively relying on these intrinsically noisy indicators for monetary policy decisions. In that respect, our critique echoes similar concerns voiced decades ago about the operational usefulness of policy based on natural rates - concerns also reflected, at least in part, in more recent discussions of monetary policy. ${ }^{17}$

A key aspect of natural rate measurement is the profound uncertainty regarding the degree of mismeasurement. Because the losses from underestimating measurement error exceed those from exaggerating it, Bayesian and robust control strategies indicate that the policy rule should incorporate a biased protection against measurement error and respond only modestly to estimates of the natural rates of interest and unemployment. Indeed, in forward-looking models, a "difference" policy rule in which the change in the interest rate responds to the inflation rate and the change in the unemployment rate, and not to levels of the natural rates, performs nearly as well as more complicated rules that incorporate both level and difference features. Only in a backward-looking model do we find a strong argument for maintaining a nontrivial response to natural rates, but even in this model the basic conclusion of our analysis holds: natural rate uncertainty implies very muted responses to both the natural rates of interest and unemployment relative to policy rules designed in the context of no measurement error. ${ }^{18}$

The historical experiences of the 1970s and the late 1990s provide insights into the design of monetary policy in light of natural rate uncertainty. In the former episode, arguably, policymakers mistakenly held to the belief that the natural rate of unemployment was lower than we now (with hindsight) believe it was, and they actively sought to stabilize

\footnotetext{
${ }^{17}$ For example, As Chairman Greenspan (2000) recently pointed out that "However one views the operational relevance of a Phillips curve or the associated NAIRU (the nonaccelerating inflation rate of unemployment) - and I am personally decidedly doubtful about it - there has to be a limit to how far the pool of available labor can be drawn down without pressing wage levels beyond productivity. The existence or nonexistence of an empirically identifiable NAIRU has no bearing on the existence of the venerable law of supply and demand."

${ }^{18}$ Interestingly, Walsh (2002) reaches similar conclusions in a recent paper that assumes no measurement problem but in which policymakers cannot commit to a policy rule. He shows that in a forward-looking model it is optimal to assign an objective of stabilizing inflation and the change in the output gap to a policymaker who acts with discretion, when the true social welfare objective is to stabilize inflation and the level of the output gap.
} 
unemployment at that level. The result was rising inflation and eventually stagflation. In the 1990s, the reverse shock took place, but inflation remained relatively stable. 


\section{References}

Akerlof, George, William Dickens and George Perry (1996), "The Macroeconomics of Low Inflation," Brookings Papers on Economic Activity, 1, 1-76.

Anderson, Gary and George Moore (1985), "A Linear Algebraic Procedure for Solving Linear Perfect Foresight Models", Economic Letters, 17, 247-252.

Ball, Laurence, and N. Gregory Mankiw (2002), "The NAIRU in Theory and Practice," NBER Working Paper 8940, May.

Ball, Laurence, and Robert R. Tchaidze (2002), "The Fed and the New Economy," American Economic Review, 92(2), 108-114, May.

Batini, Nicoletta and Andrew Haldane (1999), "Forward-looking Rules for Monetary Policy," in Taylor (1999a).

Baxter, Marianne, and Robert G. King (1999) "Measuring Business Cycles: Approximate Band-Pass Filters for Economic Time Series," Review of Economics and Statistics, 81(4), 575-593, November.

Bernanke, Ben S. and Frederic S. Mishkin (1997), "Inflation Targeting: A New Framework for Monetary Policy?" Journal of Economic Perspectives, 11(2), 97-116.

Blanchard, Olivier and Charles Kahn (1980), "The solution of linear difference models under rational expectations," Econometrica, 48(5), 1305-1311.

Blinder Alan, S. and Janet L. Yellen (2002), "The Fabulous Decade: Macroeconomic Lessons from the 1990s," in Krueger and Solow ed., New York: Russell Sage Foundation.

Bomfim, Antulio (1997), "The Equilibrium Fed Funds Rate and the Indicator Properties of Term-Structure Spreads," Economic Inquiry, 35(4), 830-46, October.

Bomfim, Antulio (2001), "Measuring Equilibrium Real Interest Rates: What can we learn from yields on indexed bonds?" manuscript, Board of Governors of the Federal Reserve System, July.

Brainard, William C. (1967), 'Uncertainty and the Effectiveness of Policy," American Economic Review, 57, 411-425.

Brainard, William C. and George C. Perry (2000), "Making Policy in a Changing World," in Economic Events, Ideas, and Policies: the 1960s and After, edited by George L. Perry and James Tobin, Washington, DC: The Brookings Institution.

Bryant, Ralph C., Peter Hooper and Catherine Mann eds. (1993), Evaluating Policy Regimes: New Research in Empirical Macroeconomics, Washington, DC: The Brookings Institution.

Burns, Arthur (1979), The Anguish of Central Banking, The 1979 Per Jacobsson Lecture, Belgrade, Yugoslavia, September 30.

Cassel, Gustav (1928), "The Rate of Interest, the Bank Rate, and the Stabilization of Prices," Quarterly Journal of Economics, 42(4), August, 511-529.

Christiano, Laurence J. and Terry J. Fitzgerald (2002), "The Band Pass Filter," International Economic Review, forthcoming. 
Clarida, Richard, Jordi Gali, and Mark Gertler (1999), "The Science of Monetary Policy," Journal of Economic Literature, 37(4), 1661-1707, December.

Congressional Budget Office (2001), "CBO's Method for Estimating Potential Output: An Update," Washington, DC: Government Printing Office (August).

Congressional Budget Office (2002), The Budget and Economic Outlook: An Update. Washington DC: Government Printing Office (August).

Croushore, Dean (1993), "Introducing: The Survey of Professional Forecasters," Federal Reserve Bank of Philadelphia Business Review, November/December, 3-13.

Croushore, Dean and Tom Stark (2001), "A Real-Time Data Set for Macroeconomists," Journal of Econometrics 105, 111-130, November.

Ehrmann, Michael and Frank Smets (2002) "Uncertain potential output: implications for monetary policy, Journal of Economic Dynamics and Control, forthcoming.

Estrella, Arturo, and Jeffrey Fuhrer (2002), "Dynamic Inconsistencies: Counterfactual Implications of a Class of Rational Expectations Models." American Economic Review, forthcoming.

Friedman, Milton (1968), "The Role of Monetary Policy," American Economic Association Papers and Proceedings, 58(1), March, 1-17.

Fuhrer, Jeffrey C. and George R. Moore (1995a) "Inflation Persistence," Quarterly Journal of Economics, 110(1), 127-59.

Fuhrer, Jeffrey C. and George R. Moore (1995b) "Forward-Looking Behavior and the Stability of a Conventional Monetary Policy Rule," Journal of Money, Credit and Banking, 27(4, Part 1), 1060-1070, November.

Goodfriend, Marvin, and Robert King (1997), "The New Neoclassical Synthesis and the Role of Monetary Policy," NBER Macroeconomics Annual, (12), 231-283.

Gordon, Robert J. (1998), "Foundations of the Goldilocks Economy: Supply Shocks and the Time-Varying NAIRU," Brookings Papers on Economic Activity, 2, 297-333.

Gordon, Robert J. (2002), Macroeconomics, Eighth Edition, New York: Harper Collins.

Greenspan, Alan (2000), "Technology and the economy," Remarks Technology and the economy Before the Economic Club of New York, New York, New York January 13.

Hall, Robert E. (1970), "Why Is the Unemployment Rate So High at Full Employment?" Brookings Papers on Economic Activity, 3, 369-402.

Hansen, Lars Peter, and Thomas J. Sargent (2002), Robust Control amd Model Uncertainty in Macroeconomics monograph, in process.

Heller, Walter W. (1966), New Dimensions of Political Economy, Cambridge, MA: Harvard University.

Hodrick, Robert J., and Edward L. Prescott, "Post-war Business Cycles: An Empirical Investigation," Journal of Money, Credit, and Banking, 29, 1997, 1-16.

Jones, Sidney L. (2000), Public $\&$ Private Economic Adviser: Paul W. McCracke, Lanham, MD: University Press. 
Judd, John P. and Brian Motley (1992), "Controlling Inflation with an Interest Rate Instrument," Federal Reserve Bank of San Francisco Economic Review, No. 3, 3-22.

Katz, Lawrence F, and Alan B. Krueger (1999), "The High-Pressure U.S. Labor Market of the 1990s" Brookings Papers on Economic Activity, 1, 2-87.

Lansing, Kevin J. (2002)," Real-time Estimation of Trend Output and the Illusion of Interest Rate Smoothing," Federal Reserve Bank of San Francisco Economic Review, 17-34.

Laubach, Thomas (2001), "Measuring the NAIRU: Evidence from Seven Economies," Review of Economics and Statistics, 83(2), May, 218-231.

Laubach, Thomas and John C. Williams (2002), "Measuring the Natural Rate of Interest," Review of Economics and Statistics, forthcoming.

Leitemo, Kai, and Ingum Lonning (2002), "Monetary Policymaking without the Output Gap," Norges Bank (October).

Levin, Andrew, Volker Wieland and John Williams (1999), "Robustness of Simple Monetary Policy Rules under Model Uncertainty," in Taylor (1999a).

Levin, Andrew, Volker Wieland and John Williams (2001), "The Performance of ForecastBased Policy Rules under Model Uncertainty," American Economic Review, forthcoming.

Levin, Andrew and John C. Williams (2002), "Robust Monetary Policy with Competing Reference Models," Federal Reserve Bank of San Francisco, mimeo.

McCallum, Bennett T. 1988), "Robustness Properties of a Rule for Monetary Policy," Carnegie-Rochester Conference Series on Public Policy, 29, Autumn, 175-203.

McCallum, Bennett (2001) "Should Monetary Policy Respond Strongly to Output Gaps?" American Economic Review, 91(2), 258-262, May.

McCallum, Bennett T. and Edward Nelson (1999), "Performance of Operational Policy Rules in an Estimated Semiclassical Structural Model." in Taylor (1999a).

Meyer, Laurence (2000), "The New Economy Meets Supply and Demand," Remarks Before the Boston Economics Club, June 6.

Meyer, Laurence, Eric Swanson, adn Volker Wieland (2001), "NAIRU Uncertainty and Nonlinear Policy Rules," Board of Governors of the Federal Reserve System (January).

Modigliani, Franco, and Lucas Papademos (1975), "Targets for Monetary Policy in the Coming Year," Brookings Papers on Economic Activity, 1, 141-163.

Neiss, Katharine S. and Edward Nelson (2001), "The Real Interest Rate Gap as an Inflation Indicator," Bank of England working paper No. 130 (April).

Nelson, Edward and Kalin Nikolov, "UK inflation in the 1970s and 1980s: the role of output gap mismeasurement," Bank of England Working Paper no. 148 and CEPR Discussion Paper no. 2,999.

Nelson, Edward and Kalin Nikolov, "Monetary Policy and stagflation in the U.K." Bank of England Working Paper 155, London: Bank of England.

Okun, Arthur (1962), "Potential Output: Its Measurement and Significance," in American Statistical Association 1962 Proceedings of the Business and Economic Section, Washington, D.C.: American Statistical Association. 
Okun, Arthur (1970), The Political Economy of Prosperity, Brookings, Washington D.C.

Okun, Arthur M., and Nancy H. Teeters (1970), "The Full Employment Surplus Revisited," Brookings Papers on Economic Activity, 1, 77-110.

Orphanides, Athanasios (1998), "Monetary Policy Evaluation With Noisy Information," Finance and Economics Discussion Series, 1998-50, Federal Reserve Board, October.

Orphanides, Athanasios (2000a), "Activist Stabilization Policy and Inflation: The Taylor Rule in the 1970s," Finance and Economics Discussion Series, 2000-13, Federal Reserve Board, February.

Orphanides, Athanasios (2000b), "The Quest for Prosperity Without Inflation," European Central Bank Working Paper No. 15, March.

Orphanides, Athanasios (2001), "Monetary Policy Rules Based on Real-Time Data," American Economic Review, September.

Orphanides, Athanasios (2002a), "Monetary Policy Rules and the Great Inflation," American Economic Review, 92(2), 115-120, May.

Orphanides, Athanasios (2002b), "Historical Monetary Policy Analysis and the Taylor Rule," Board of Governors of the Federal Reserve System (November).

Orphanides, Athanasios, Richard Porter, David Reifschneider, Robert Tetlow and Frederico Finan (2000), "Errors in the Measurement of the Output Gap and the Design of Monetary Policy," Journal of Economics and Business, 52(1/2), 117-141, January/April.

Orphanides, Athanasios and Volker Wieland (1998), "Price Stability and Monetary Policy Effectiveness when Nominal Interest Rates are Bounded at Zero", Finance and Economics Discussion Series Working Paper 1998-35, Board of Governors of the Federal Reserve System.

Orphanides, Athanasios and Simon van Norden (2001) "The Reliability of Inflation Forecasts Based on Output Gap Estimates in Real Time," mimeo, September.

Orphanides, Athanasios and Simon van Norden (2002) "The Unreliability of Output Gap Estimates in Real Time," Review of Economics and Statistics, November, forthcoming.

Orphanides, Athanasios and John C. Williams (2002) "Imperfect Knowledge, Inflation Expectations and Monetary Policy," Finance and Economics Discussion Series, 2002-27, Federal Reserve Board, June.

Perry, George L. (1970), "Changing Labor Markets and Inflation," Brookings Papers on Economic Activity, 3, 411-448.

Phillips, A. W. (1954), "Stabilisation Policy in a Closed Economy," Economic Journal, 290-323, June.

Poole, William (1971), "Alternative Paths to s Stable Full Employment Economy," Brookings Papers on Economic Activity, 3, 579-606.

Reifschneider, David, and John Williams (2000), "Three Lessons for Monetary Policy in a Low Inflation Era," Journal of Money, Credit and Banking, 32(4), 936-66, November

Roberts, John M. (1997), "Is Inflation Sticky?" Journal of Monetary Economics, 39, 173196. 
Roberts, John M. (2001), "How Well Does the New Keynesian Stick-Price Model Fit the Data?" Finance and Economics Discussion Series, 2001-13, Federal Reserve Board (February).

Romer, Christina D. and David H. Romer (2000), "Federal Reserve Information and the Behavior of Interest Rates," American Economic Review, 90(3), June, 429-457.

Rotemberg, Julio J. (1999), "A Heuristic Method for Extracting Smooth Trends from Economic Time Series," NBER Working Paper No. 7439 (December).

Rotemberg, Julio J. and Michael Woodford (1999), "Interest Rate Rules in an Estimated Sticky Price Model," in Taylor (1999a).

Rudebusch, Glenn (2001), "Is the Fed Too Timid? Monetary Policy in an Uncertain World" Review of Economics and Statistics, 83(2), 203-17, May.

Rudebusch, Glenn (2002) "Assessing Nominal Income Rules for Monetary policy with Model and Data Uncertainty," Economic Journal, 112, 402-432, April.

Rudebusch, Glenn and Lars Svensson (1999), "Policy Rules for Inflation Targeting" in Taylor (1999a).

Sack, Brian, and Volker Wieland (2000) "Interest-Rate Smoothing and Optimal Monetary Policy: A Review of Recent Empirical Evidence" Journal of Economics and Business, 52(1/2), 205-228, January/April.

Sargent, Thomas J. (1971) "A Note on the 'Accelerationist' Controversy," Journal of Money, Credit and Banking, 3(3), 721-725, August.

Shimer, Robert (1998), "Why is the Unemployment Rate So Much Lower" in NBER Macroeconomics Annual 1998, ed. by Benjamin S. Bernanke and Julio J. Rotemberg, 11-60.

Smets, Frank (2000), "What Horizon for Price Stability," European Central Bank Working Paper No 24.

Smets, Frank (2002), "Output Gap Uncertainty: Does it Matter for the Taylor Rule?" Empirical Economics, 22(1), 113-29.

St. Amant, Pierre and Simon van Norden (1997), "Measurement of the Output Gap: A discussion of recent research at the Bank of Canada," Bank of Canada Technical Report No. 79 (1997).

Social Security Administration (various years) , Annual Report of the Board of Trustees of the Federal Old-age and Survivors Insurance and Disability Insurance Trust Funds, Washington, DC.

Staiger, Douglas, James H. Stock, and Mark W. Watson (1997a), "How Precise are Estimates of the Natural rate of Unemployment?" in: Reducing Inflation: Motivation and Strategy, ed. by Christina D. Romer and David H. Romer, Chicago: University of Chicago Press. 195-246.

Staiger, Douglas, James H. Stock, and Mark W. Watson (1997b), "The NAIRU, Unemployment, and Monetary Policy," Journal of Economic Perspectives, 11, 33-51, Winter.

Staiger, Douglas, James H. Stock, and Mark W. Watson (2002), "Prices, Wages, and the U.S. NAIRU in the 1990s," in Krueger and Solow ed. (2002) 
Stein, Herbert (1984), Presidential Economics, New York: Simon and Schuster.

Stock, James H. and Mark W. Watson (1998), "Median Unbiased Estimation of Coefficient Variance in a Time-Varying Parameter Model," Journal of the American Statistical Association, 93, 349-358, March.

Stock, James H. and Mark W. Watson, "Forecasting Inflation," Journal of Monetary Economics, 44, 293-335, 1999.

Svensson, Lars and Michael Woodford (2002), "Indicator Variables for Optimal Policy," Journal of Monetary Economics, forthcoming.

Swanson, Eric T. (2000), "On Signal Extraction and Non-Certainty-Equivalence in Optimal Monetary Policy Rule," Finance and Economics Discussion Series, 2000-32, Board of Governors of the Federal Reserve System, June.

Taylor, John B. (1993), "Discretion versus Policy Rules in Practice," Carnegie-Rochester Conference Series on Public Policy, 39, December, 195-214.

Taylor, John B., ed., (1999a), Monetary Policy Rules, Chicago: University of Chicago.

Taylor, John B. (1999b), "The Robustness and Efficiency of Monetary Policy Rules as Guidelines for Interest Rate Setting by the European Central Bank," Journal of Monetary Economics, 43(3), 655-679.

Taylor, John B. and Michael Woodford, eds. (1999), Handbook of Macroeconomics, Amsterdam: Elsevier.

van Norden, Simon (2002), "Filtering for Current Analysis" Bank of Canada Working Paper.

Walsh, Carl E. (2002), "Speed Limit Policies: The Output Gap and Optimal Monetary Policy," American Economic Review, forthcoming.

Wicksell, Knut (1898), Interest and Prices, 1936 translation from the German by R. F. Kahn, London: Macmillan.

Wieland, Volker (1998), "Monetary Policy and Uncertainty about the Natural Unemployment Rate," Finance and Economics Discussion Series, 98-22, Board of Governors of the Federal Reserve System, May.

Williams, John C. (1999), "Simple Rules for Monetary Policy," Finance and Economics Discussion Series, 99-12, Board of Governors of the Federal Reserve System, February.

Williams, John H. (1931), "The Monetary Doctrines of J. M. Keynes" Quarterly Journal of Economics, 45(4), August, 547-587.

Woodford, Michael (1999), "Optimal Monetary Policy Inertia," NBER Working Paper 7261 (July).

Woodford, Michael (2002), Interest and Prices: Foundations of a Theory of Monetary Policy, manuscript.

Zarnowitz, Victor and Phillip A. Braun (1993), "Twenty-two Years of the NBER-ASA Quarterly Economic Outlook Surveys: Aspects and Comparisons of Forecasting Performance," in Stock and Watson (1993). 
Table 1. Retrospective Estimates of the Natural Rate of Unemployment

\begin{tabular}{|c|c|c|c|c|c|}
\hline Source or method & 1960 & 1970 & 1980 & 1990 & 2000 \\
\hline Congressional Budget Office $(2002)^{1}$ & 5.5 & 5.9 & 6.2 & 5.9 & 5.2 \\
\hline Gordon $(2002)^{1}$ & 5.6 & 6.3 & 6.3 & 6.2 & 5.0 \\
\hline Ball and Mankiw method ${ }^{2}$ & 5.0 & 6.0 & 6.9 & 6.2 & 4.5 \\
\hline Staiger, Stock, and Watson $(2002)^{1}$ & 5.8 & 4.7 & 7.7 & 6.3 & 4.5 \\
\hline Kalman filter ${ }^{2}$ & - & 5.7 & 6.4 & 5.8 & 5.0 \\
\hline Brainard and Perry $(2000)^{1}$ & 3.8 & 4.7 & 9.8 & 5.8 & $3.8^{3}$ \\
\hline Shimer $(1998)^{1}$ & 5.3 & 6.5 & 7.1 & 5.9 & 5.9 \\
\hline BP filter (8-year window $)^{2}$ & 6.0 & 4.2 & 7.3 & 5.9 & 4.9 \\
\hline BP filter (15-year window $)^{2}$ & 5.6 & 4.4 & 7.9 & 6.3 & 5.0 \\
\hline HP filter $(\lambda=1600)^{2}$ & 5.9 & 4.6 & 7.5 & 6.1 & 4.5 \\
\hline HP filter $(\lambda=25600)^{2}$ & 5.3 & 5.0 & 7.4 & 6.4 & 4.6 \\
\hline \multicolumn{6}{|l|}{ Memoranda: } \\
\hline Median of estimates & 5.6 & 5.0 & 7.3 & 6.1 & 4.9 \\
\hline Range of extimates & $3.8-5.9$ & $4.2-6.5$ & $6.2-9.8$ & $5.8-6.4$ & $3.8-5.9$ \\
\hline Actual unemployment rate & 5.5 & 5.0 & 7.2 & 5.6 & 4.0 \\
\hline
\end{tabular}

Notes:

1. Estimates are taken from the indicated source, in some cases updated by source author.

2. Estimates are authors' calculations, based on methods described in sources cited in the text.

3. Estimate is for 1998. 
Table 2. Forecast Errors of Alternative Natural Rate-Based and Autoregressive Methods

\begin{tabular}{lccc}
\hline & \multicolumn{3}{c}{ Standard error of the regression } \\
\cline { 2 - 4 } Method & $\begin{array}{c}\text { 1-quarter } \\
\text { horizon }\end{array}$ & $\begin{array}{c}\text { 4-quarter } \\
\text { horizon }\end{array}$ & $\begin{array}{c}\text { 8-quarter } \\
\text { horizon }\end{array}$ \\
\hline Forecasting inflation & \\
Constant natural rate of unemployment & & & \\
Kalman filter & 1.11 & 1.12 & 1.74 \\
Ball and Mankiw method & 1.10 & 1.14 & 1.80 \\
BP filter (8-year window) & 1.14 & 1.11 & 1.73 \\
BP filter(15-year window) & 1.10 & 1.13 & 1.78 \\
HP filter( $\lambda=1600)$ & 1.11 & 1.16 & 1.74 \\
HP filter( $\lambda=25600)$ & 1.13 & 1.13 & 1.79 \\
AR(4) (no unemployment rate term) & 1.14 & 1.16 & 1.80 \\
& 1.18 & 1.24 & 1.92 \\
Unemployment rate & & & \\
Constant natural rate of interest & & & \\
Kalman filter & 0.26 & 0.55 & 1.10 \\
Laubach and Williams method & 0.25 & 0.52 & 1.07 \\
BP filter (8-year window) & 0.26 & 0.54 & 1.11 \\
BP filter (15-year window) & 0.26 & 0.53 & 1.09 \\
HP filter $(\lambda=1600)$ & 0.25 & 0.52 & 1.06 \\
HP filter $(\lambda=25600)$ & 0.26 & 0.54 & 1.07 \\
AR(2) (no real rate term) & 0.25 & 0.51 & 1.03 \\
\hline
\end{tabular}

Notes:

1. The sample period is 1970:1-2002:2. For the one-quarter forecast horizon the forecast rate is that in the next quarter; for the four-quarter forecast horizon it is the average of the next four quarters; for the eight-quarter horizon it is the average of the subsequent four quarters.

2. All except the AR(4) equation include four lags of inflation, one lag of the change in the unemployment rate, and two lags of the unemployment gap.

3. All except the $\operatorname{AR}(2)$ equation include two lags of the unemployment rate gap and one lag of the four-quarter moving average of the real rate gap. 
Table 3. Natural Rate Misperceptions Assuming the Model is Known ${ }^{1}$

\begin{tabular}{lccc}
\hline & $\begin{array}{c}\text { Standard deviation } \\
\text { of difference between } \\
\text { real-time and } \\
\text { retrospective } \\
\text { estimates }\end{array}$ & $\begin{array}{c}\text { Persistence } \\
\text { coefficient }\end{array}$ & $\begin{array}{c}\text { Standard error } \\
\text { of regression }\end{array}$ \\
& & & $\sigma_{\nu}$ \\
\hline Method or source & & & \\
Natural rate of unemployment & 0.66 & 0.95 & 0.21 \\
Kalman filter & 0.58 & 0.97 & 0.14 \\
Ball-Mankiw method & 0.52 & 0.89 & 0.23 \\
BP filter (8-year window) & 0.61 & 0.92 & 0.23 \\
BP filter(15-year window) & 0.75 & 0.97 & 0.18 \\
HP filter( $\lambda=1600)$ & 0.78 & 0.98 & 0.12 \\
HP filter( $\lambda=25600)$ & & & \\
& & & \\
Natural rate of interest & 1.44 & 0.93 & 0.55 \\
Kalman filter & 0.90 & 0.91 & 0.38 \\
Laubach-Williams & 1.04 & 0.92 & 0.42 \\
BP filter(8-year window) & 1.34 & 0.96 & 0.41 \\
BP filter(15-year window) & 1.26 & 0.96 & 0.37 \\
HP filter( $\lambda=1600)$ & 1.70 & 0.99 & 0.25 \\
HP filter( $\lambda=25600)$ & &
\end{tabular}

Note:

1. For each method, the real-time misperception is defined as the difference between the real-time and the retrospective estimate of the natural rate. The sample period for these statistics is 1969:1-1998:2. 
Table 4. Misperceptions of the Natural Rates Allowing for Model Uncertainty

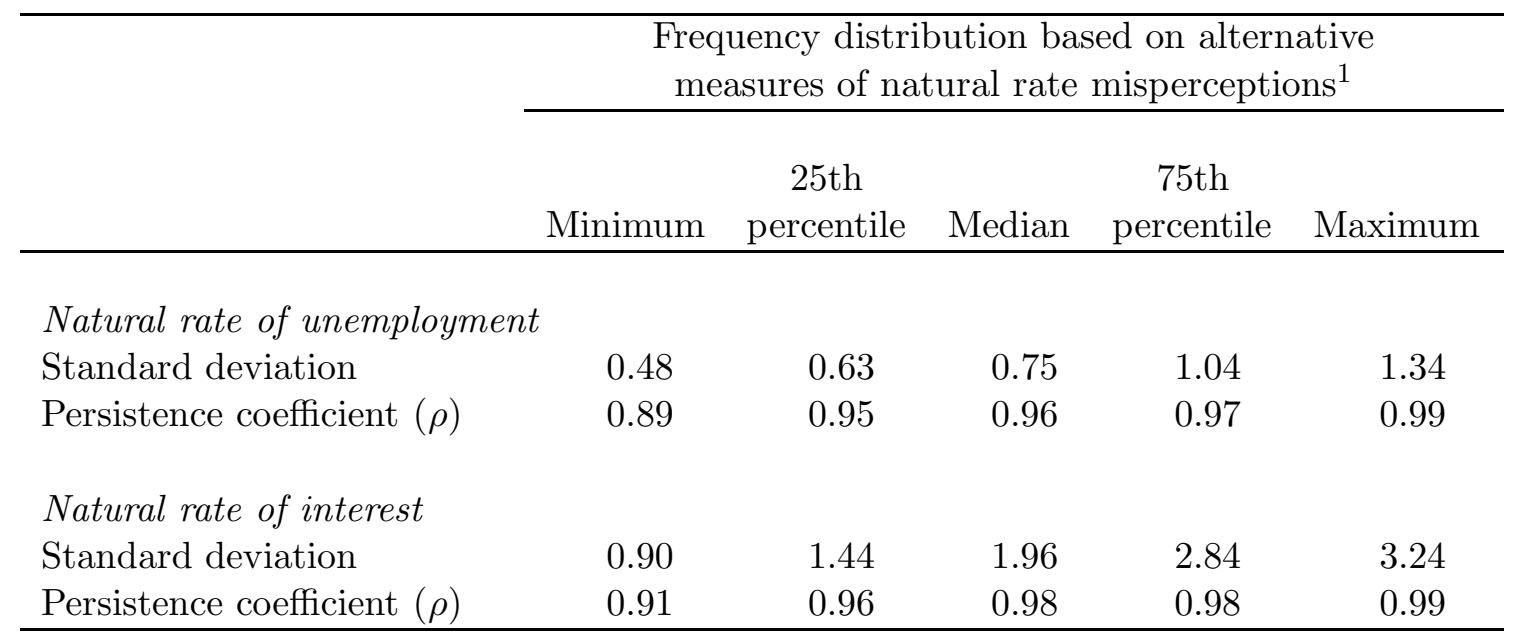

Note:

1. The sample is the thirty-six alternative measures of natural rate misperceptions corresponding to all possible pairwise combinations of the six methods listed in each panel of Table 3. Each of the two statistics is computed separately. 
Table 5. Macroeocnomic Performance under Alternative Policy Rules

\begin{tabular}{|c|c|c|c|c|c|c|c|c|}
\hline \multirow{2}{*}{$\begin{array}{l}\text { Rule and } \\
\text { misperception index }{ }^{1}\end{array}$} & \multicolumn{4}{|c|}{ Rule parameter ${ }^{2}$} & \multicolumn{3}{|c|}{ Standard deviation $^{3}$} & \multirow{2}{*}{$\begin{array}{c}\text { Loss } \\
(\omega=0.2 \\
(\psi=0.05)\end{array}$} \\
\hline & $\theta_{f}$ & $\theta_{\pi}$ & $\theta_{u}$ & $\theta_{\Delta u}$ & $u-u *$ & $\pi$ & $\Delta f$ & \\
\hline \multicolumn{9}{|l|}{ Classic Taylor rule } \\
\hline$s=0$ & 0.0 & 0.5 & -1.0 & 0.0 & 0.81 & 2.14 & 2.83 & 1.84 \\
\hline$s=1$ & 0.0 & 0.5 & -1.0 & 0.0 & 0.88 & 3.67 & 2.88 & 3.73 \\
\hline$s=2$ & 0.0 & 0.5 & -1.0 & 0.0 & 1.01 & 6.11 & 3.38 & 8.85 \\
\hline$s=3$ & 0.0 & 0.5 & -1.0 & 0.0 & 1.18 & 8.72 & 4.15 & 17.18 \\
\hline \multicolumn{9}{|l|}{ Revised Taylor rule } \\
\hline$s=0$ & 0.0 & 0.5 & -2.0 & 0.0 & 0.71 & 2.03 & 2.89 & 1.64 \\
\hline$s=1$ & 0.0 & 0.5 & -2.0 & 0.0 & 0.77 & 4.13 & 2.91 & 4.32 \\
\hline$s=2$ & 0.0 & 0.5 & -2.0 & 0.0 & 0.91 & 7.28 & 3.56 & 11.89 \\
\hline$s=3$ & 0.0 & 0.5 & -2.0 & 0.0 & 1.09 & 10.57 & 4.59 & 24.36 \\
\hline \multicolumn{9}{|c|}{ Taylor rule optimized for $s=0$} \\
\hline$s=0$ & 0.0 & 0.31 & -3.81 & 0.0 & 0.61 & 2.05 & 2.83 & 1.54 \\
\hline$s=1$ & 0.0 & 0.31 & -3.81 & 0.0 & 0.71 & 7.15 & 3.09 & 11.11 \\
\hline$s=2$ & 0.0 & 0.31 & -3.81 & 0.0 & 0.94 & 13.64 & 4.54 & 38.94 \\
\hline$s=3$ & 0.0 & 0.31 & -3.81 & 0.0 & 1.22 & 20.22 & 6.41 & 85.05 \\
\hline \multicolumn{9}{|c|}{ Taylor rule optimized for $s=1$} \\
\hline$s=0$ & 0.0 & 1.37 & -1.23 & 0.0 & 0.73 & 1.86 & 4.25 & 2.02 \\
\hline$s=1$ & 0.0 & 1.37 & -1.23 & 0.0 & 0.79 & 2.07 & 4.90 & 2.56 \\
\hline$s=2$ & 0.0 & 1.37 & -1.23 & 0.0 & 0.82 & 2.50 & 4.94 & 3.01 \\
\hline$s=3$ & 0.0 & 1.37 & -1.23 & 0.0 & 0.86 & 3.05 & 5.11 & 3.76 \\
\hline \multicolumn{9}{|c|}{ Generalized rule optimized for $s=0$} \\
\hline$s=0$ & 0.72 & 0.26 & -1.83 & -2.39 & 0.62 & 1.82 & 2.23 & 1.23 \\
\hline$s=1$ & 0.72 & 0.26 & -1.83 & -2.39 & 0.70 & 4.49 & 2.32 & 4.71 \\
\hline$s=2$ & 0.72 & 0.26 & -1.83 & -2.39 & 0.95 & 8.36 & 3.01 & 15.16 \\
\hline$s=3$ & 0.72 & 0.26 & -1.83 & -2.39 & 1.27 & 12.35 & 4.00 & 32.58 \\
\hline \multicolumn{9}{|c|}{ Generalized rule optimized for $s=1$} \\
\hline$s=0$ & 0.97 & 0.39 & -0.23 & -5.39 & 0.66 & 1.94 & 2.45 & 1.40 \\
\hline$s=1$ & 0.97 & 0.39 & -0.23 & -5.39 & 0.66 & 1.95 & 2.42 & 1.40 \\
\hline$s=2$ & 0.97 & 0.39 & -0.23 & -5.39 & 0.66 & 2.08 & 2.40 & 1.50 \\
\hline$s=3$ & 0.97 & 0.39 & -0.23 & -5.39 & 0.66 & 2.32 & 2.40 & 1.71 \\
\hline \multicolumn{9}{|l|}{ Robust difference rule } \\
\hline$s=\infty$ & 1.0 & 0.35 & 0.0 & -5.96 & 0.66 & 2.01 & 2.49 & 1.46 \\
\hline
\end{tabular}

Notes:

1. $s$ indexes the magnitude of policymakers' misperception of the true natural rates.

2. Parameters measure policymakers' response to the lagged federal funds rate, the inflation gap, the unemployment gap, and the change in the unemployment rate, respectively.

3. Unconditional standard deviation of the unemployment gap, the inflation rate, and the change in the federal funds rate, respectively. 
Table 6. Robust Policy Rule Parameters under Alternative Policymaker Preferences ${ }^{1}$

\begin{tabular}{ccccccccc}
\hline \multicolumn{2}{c}{ Loss parameters } & & \multicolumn{3}{c}{ Rule parameter ${ }^{2}$} & & \multicolumn{3}{c}{ Standard deviation } \\
\cline { 1 - 2 } \cline { 7 - 9 }$\omega$ & $\psi$ & & $\theta_{\pi}$ & $\theta_{\Delta u}$ & & $u-u *$ & $\pi$ & $\Delta f$ \\
\hline 0.5 & 0.05 & & 0.57 & -6.29 & & 0.67 & 1.94 & 2.78 \\
0.5 & 0.50 & & 0.25 & -3.56 & & 0.82 & 2.22 & 1.77 \\
0.5 & 5.00 & & 0.13 & -2.43 & & 1.05 & 2.67 & 1.48 \\
& & & & & & & \\
0.2 & 0.05 & & 0.35 & -5.96 & & 0.66 & 2.01 & 2.49 \\
0.2 & 0.50 & & 0.17 & -3.34 & & 0.85 & 2.32 & 1.66 \\
0.2 & 5.00 & & 0.12 & -2.34 & & 1.09 & 2.76 & 1.46 \\
& & & & & & & \\
0.1 & 0.05 & & 0.24 & -5.79 & & 0.65 & 2.08 & 2.36 \\
0.1 & 0.50 & & 0.14 & -3.25 & & 0.87 & 2.38 & 1.62 \\
0.1 & 5.00 & 0.11 & -2.30 & & 1.11 & 2.80 & 1.46 \\
\hline
\end{tabular}

Notes:

1. See Table 5 for definitions of parameters and performance measures.

2. Parameters of the robust rule in equation (3) of the text. 
Table 7. Performance under Optimized and under Robust Rules for Alternative Models

\begin{tabular}{lccccc}
\hline & \multicolumn{5}{c}{ Loss when policy follows } \\
\cline { 2 - 6 } & & \multicolumn{5}{c}{ Robust } \\
Model & Gule & \multicolumn{4}{c}{ Generalized Taylor rule optimized for $s=0$} \\
\cline { 2 - 6 } & & True $s=0$ & True $s=1$ & True $s=2$ & True $s=3$ \\
\hline & 1.46 & 1.23 & 4.71 & 15.16 & 32.58 \\
Baseline & 0.63 & 0.56 & 0.69 & 1.02 & 1.56 \\
New-Synthesis & 5.13 & 2.19 & 2.53 & 3.54 & 5.24 \\
Accelerationist & &
\end{tabular}

Note:

1. Loss as calculated by equation (12) in the text assuming $\omega=0.2, \psi=0.05$. 
Table 8. Robust Policy Rules across Alternative Models ${ }^{1}$

\begin{tabular}{|c|c|c|c|c|c|c|}
\hline \multirow{2}{*}{\multicolumn{2}{|c|}{ Loss parameters }} & \multirow{2}{*}{\multicolumn{2}{|c|}{$\begin{array}{c}\text { Rule } \\
\text { parameter }^{2}\end{array}$}} & \multicolumn{3}{|c|}{ Loss when true model is: } \\
\hline & & & & \multirow{2}{*}{$\begin{array}{c}\text { Baseline } \\
\text { model }\end{array}$} & \multirow{2}{*}{$\begin{array}{c}\text { Accelerationist } \\
\text { model }\end{array}$} & \multirow{2}{*}{$\begin{array}{c}\text { New synthesis } \\
\text { model }\end{array}$} \\
\hline$\omega$ & $\bar{\psi}$ & $\theta_{\pi}$ & $\theta_{\Delta u}$ & & & \\
\hline 0.5 & 0.05 & 1.56 & -7.13 & 2.89 & 5.45 & 1.12 \\
\hline 0.5 & 0.50 & 0.84 & -4.23 & 5.84 & 10.19 & 2.20 \\
\hline 0.5 & 5.00 & 0.56 & -3.21 & 24.21 & 32.06 & 9.61 \\
\hline 0.2 & 0.05 & 1.28 & -7.85 & 1.88 & 5.27 & 0.74 \\
\hline 0.2 & 0.50 & 0.76 & -4.41 & 4.60 & 9.73 & 1.84 \\
\hline 0.2 & 5.00 & 0.54 & -3.26 & 22.55 & 30.72 & 9.32 \\
\hline 0.1 & 0.05 & 1.15 & -8.19 & 1.53 & 5.14 & 0.60 \\
\hline 0.1 & 0.50 & 0.72 & -4.49 & 4.17 & 9.51 & 1.72 \\
\hline 0.1 & 5.00 & 0.53 & -3.28 & 21.98 & 30.22 & 9.23 \\
\hline
\end{tabular}

Notes:

1. See Table 5 for definitions of parameters and performance measures.

2. Parameters of the robust rule (equation (3) in the text) chosen to minimize the expected loss for the indicated values of the loss parameters, when the model is unknown and each of the models is assigned equal likelihood of being the true model. Loss is calculated by equation (12) in the text. 
Table 9: Estimates of the Natural Rate of Unemployment, 1995-2002

\begin{tabular}{|c|c|c|c|c|c|c|}
\hline \multirow[b]{2}{*}{ Year } & \multicolumn{3}{|c|}{$\begin{array}{l}\text { Survey of Professional } \\
\text { Forecasters (real-time) }{ }^{1}\end{array}$} & \multicolumn{2}{|c|}{$\begin{array}{l}\text { Congressional } \\
\text { Budget Office }\end{array}$} & \multirow{2}{*}{$\begin{array}{c}\text { Council of } \\
\text { Economic } \\
\text { Advisers } \\
\text { (real-time) }\end{array}$} \\
\hline & Low & Median & High & Real-Time ${ }^{2}$ & Retrospective $^{3}$ & \\
\hline 1995 & - & - & - & 6.0 & 5.3 & $5.5-5.8$ \\
\hline 1996 & 5.00 & 5.65 & 6.00 & 5.8 & 5.2 & 5.7 \\
\hline 1997 & 4.50 & 5.25 & 5.88 & 5.8 & 5.2 & 5.5 \\
\hline 1998 & 4.50 & 5.30 & 5.80 & 5.8 & 5.2 & 5.4 \\
\hline 1999 & 4.13 & 5.00 & 5.60 & 5.6 & 5.2 & 5.3 \\
\hline 2000 & 4.00 & 4.50 & 5.00 & 5.2 & 5.2 & 5.2 \\
\hline 2001 & 3.50 & 4.88 & 5.50 & 5.2 & 5.2 & 5.1 \\
\hline 2002 & 3.80 & 5.10 & 5.50 & 5.2 & 5.2 & 4.9 \\
\hline
\end{tabular}

Notes:

1. Responses are those from the third-quarter in the indicated year.

2. Estimates are from the The Budget and Economic Outlook published in the indicated year (usually in January).

3. Estimates are from Congressional Budget Office (2002).

4. Estimates are from the Economic Report of the President published in the year shown (usually in February) and reflect either explicit references to a NAIRU estimate, or, when no explicit reference appears, the unemployment rate at the end of the long-term economic forecast presented in the report. 
Figure 1

Retrospective Estimates of the Natural Rate of Unemployment. 1969-2002

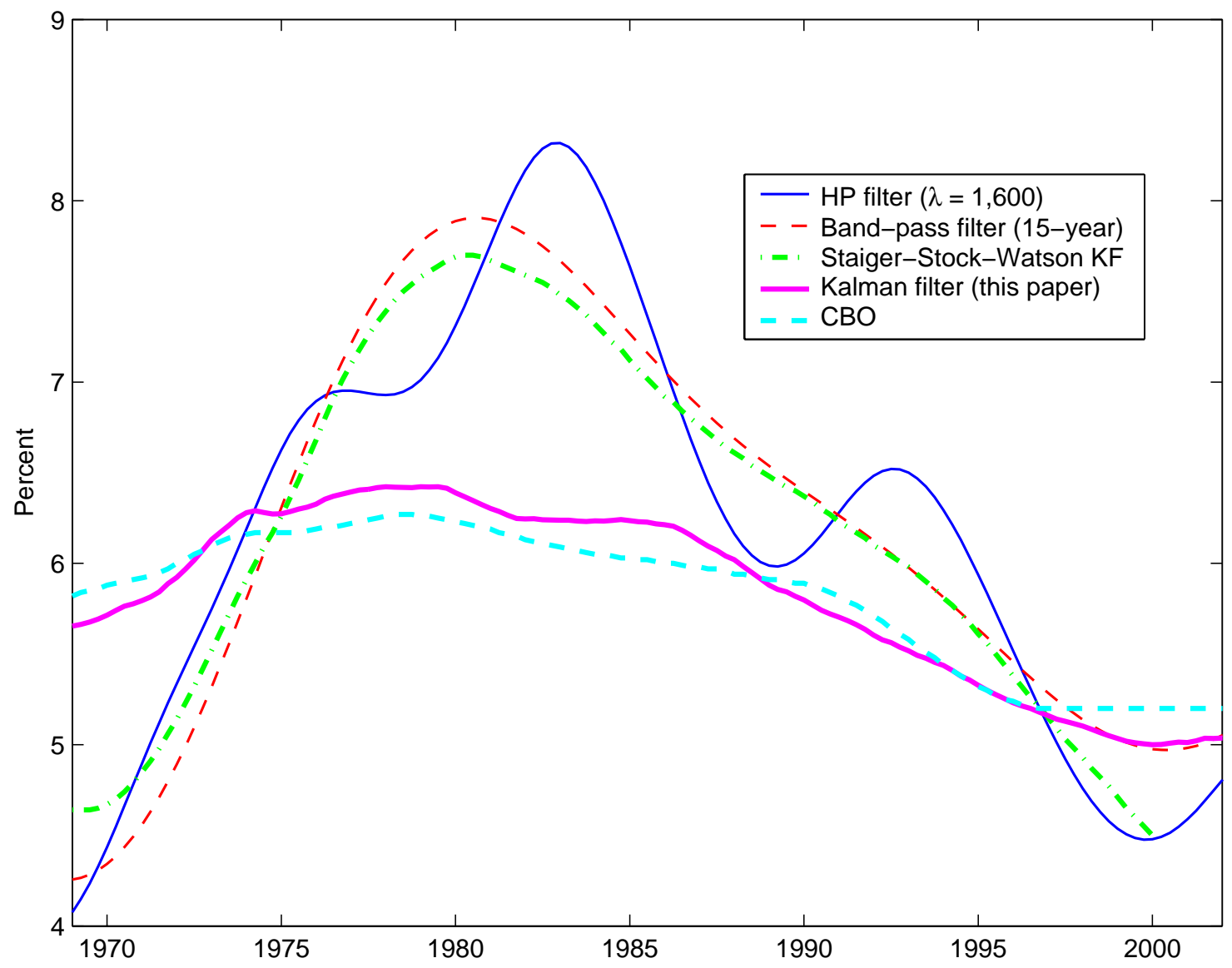


Figure 2

Real-Time Estimates of the Natural Rate of Unemployment, 1969-2002

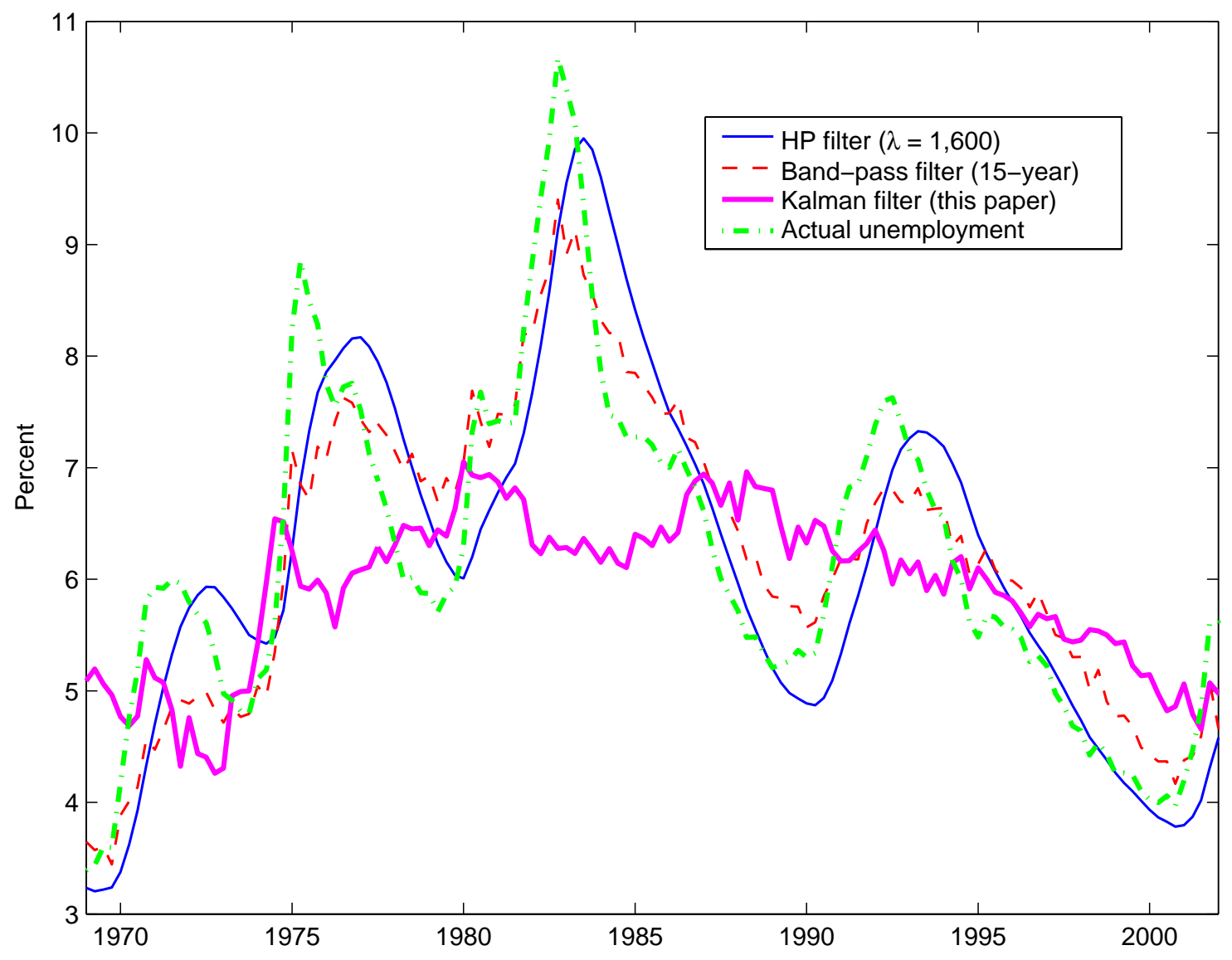


Figure 3

Retrospective Estimates of the Natural Rate of Interest, 1969-2002

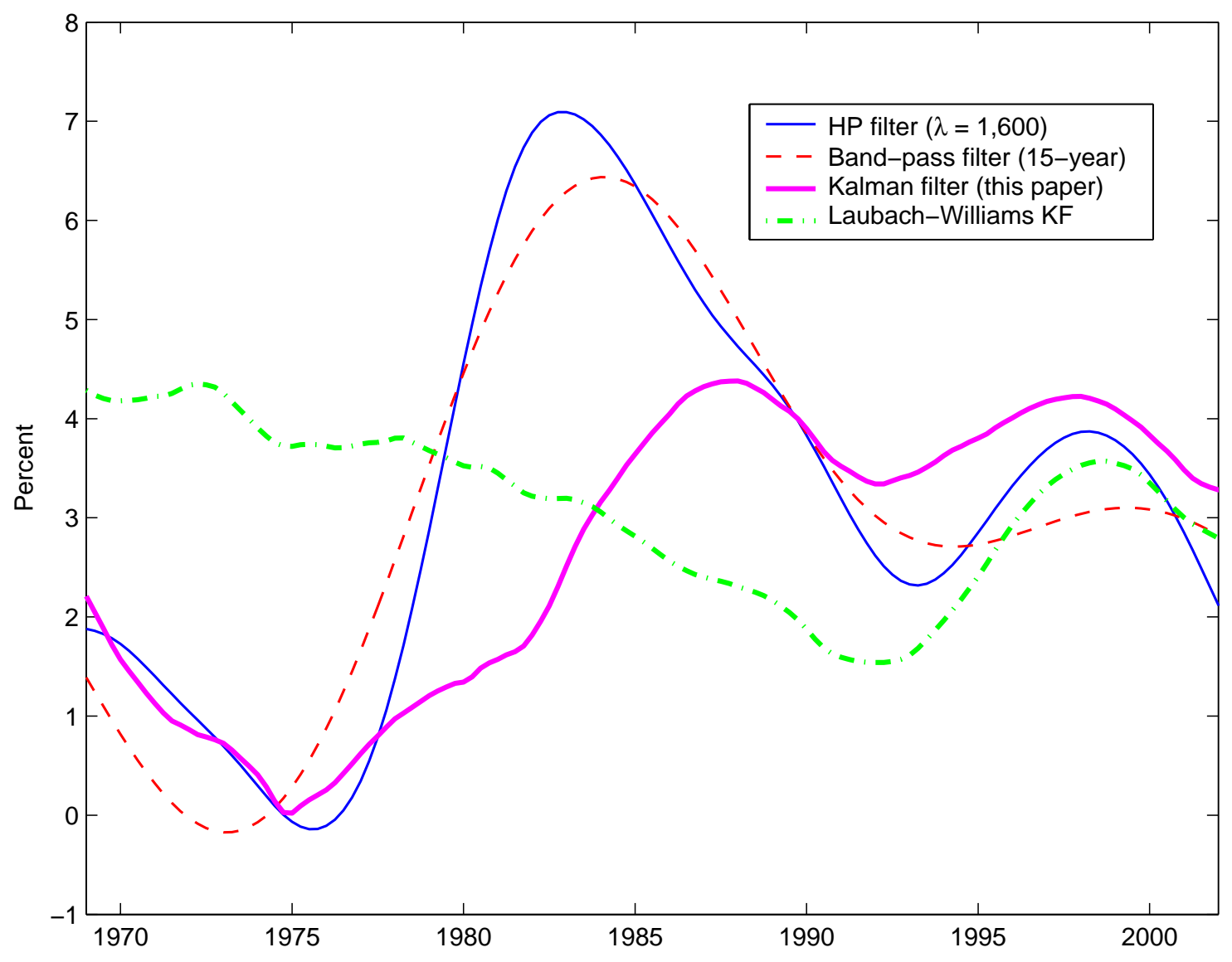


Figure 4

Real-Time Estimates of the Natural Rate of Interest, 1969-2002

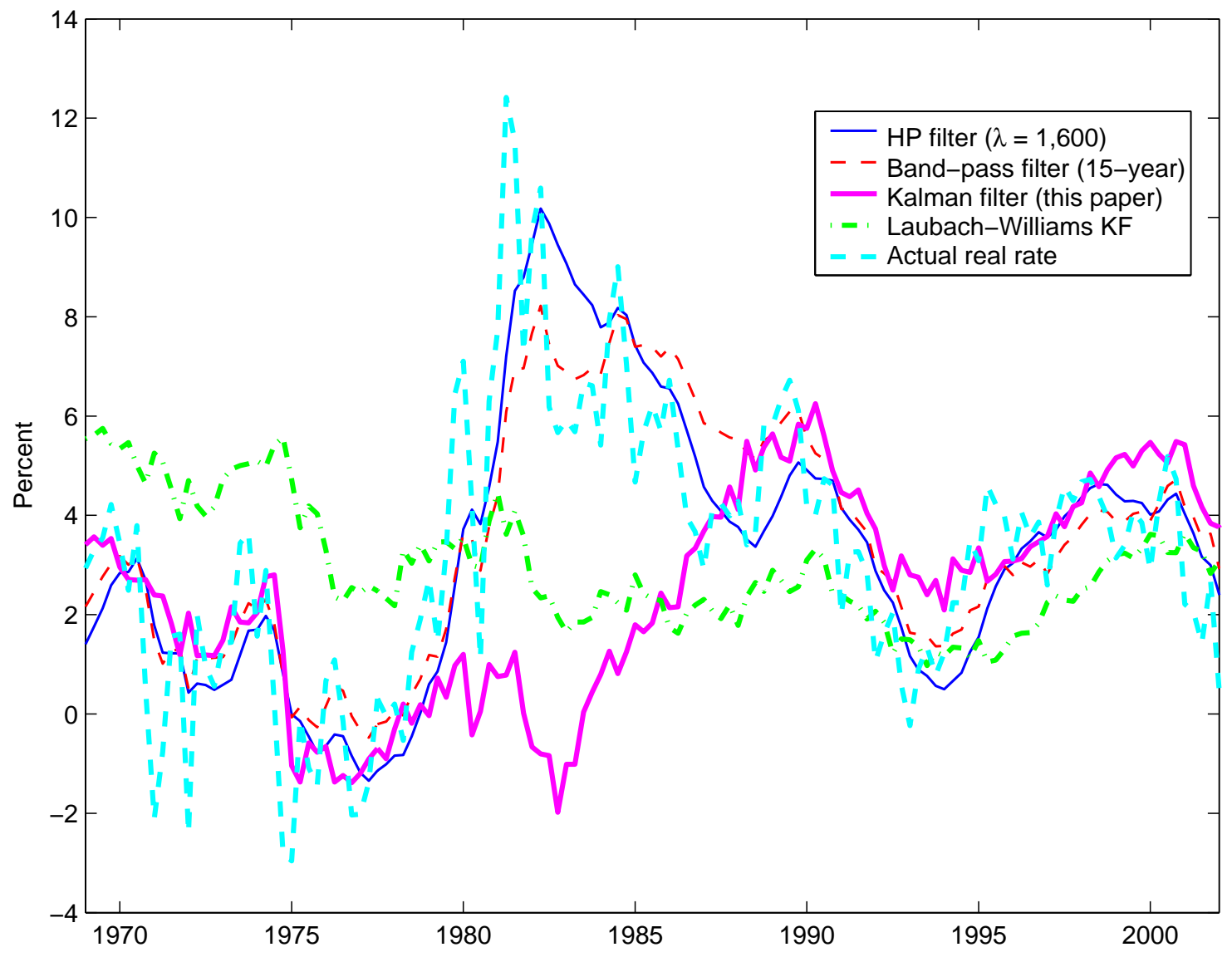


Figure 5

Macroeconomic Performance of Taylor Rules for Given Degrees of Natural Rate Misperceptions
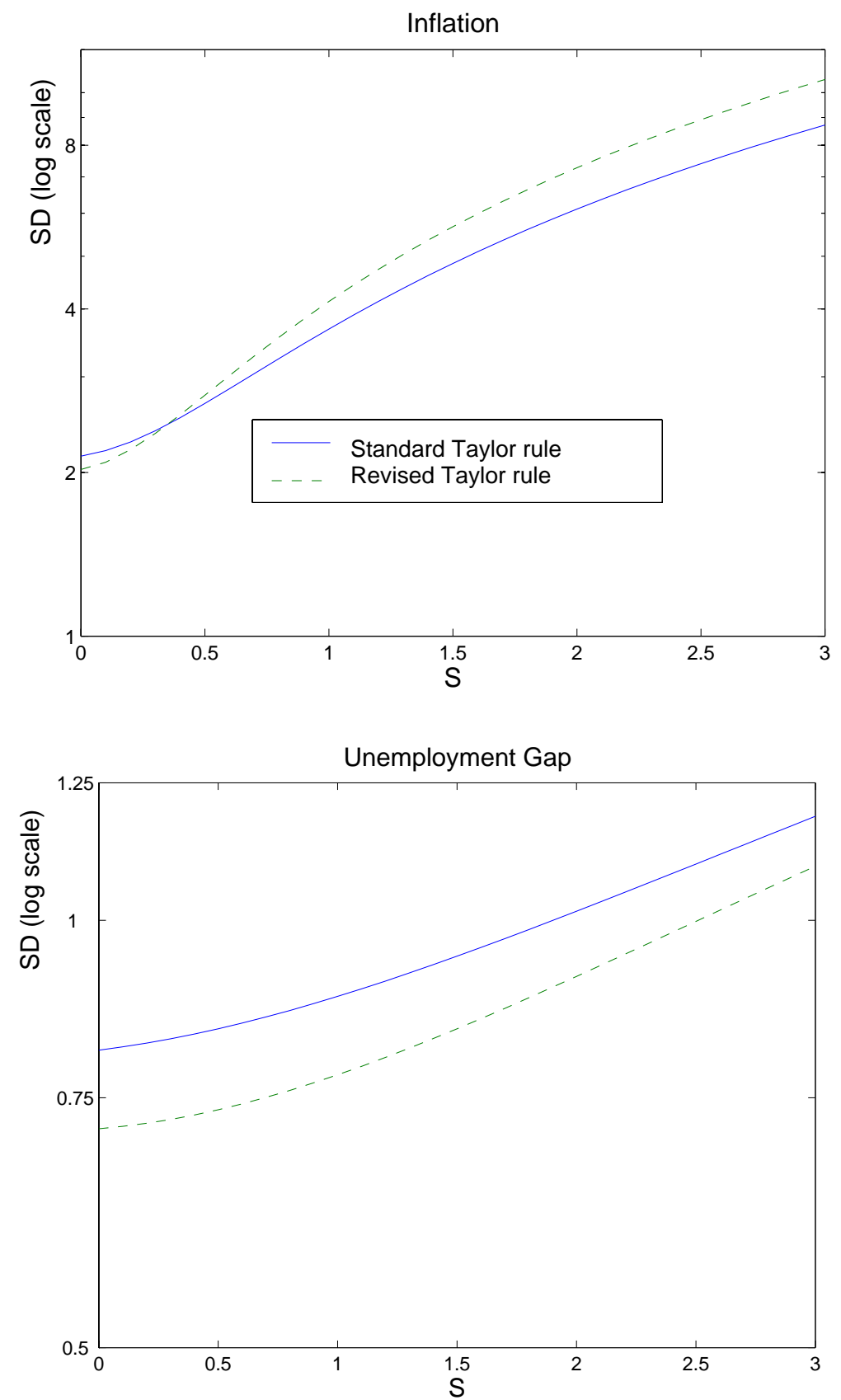

Notes: The two panels show the asymptotic standard deviation of inflation and the unemployment gap (vertical axis, in percent) corresponding to the degree of misperceptions regarding the natural rates, $s$ (horizontal axis) when policy follows the original and revised Taylor rules, reflected by the solid and dashed lines, respectively. 
Figure 6

Optimal Policy Response Parameters under Taylor Rules for Given Degrees of Natural Rate Misperceptions
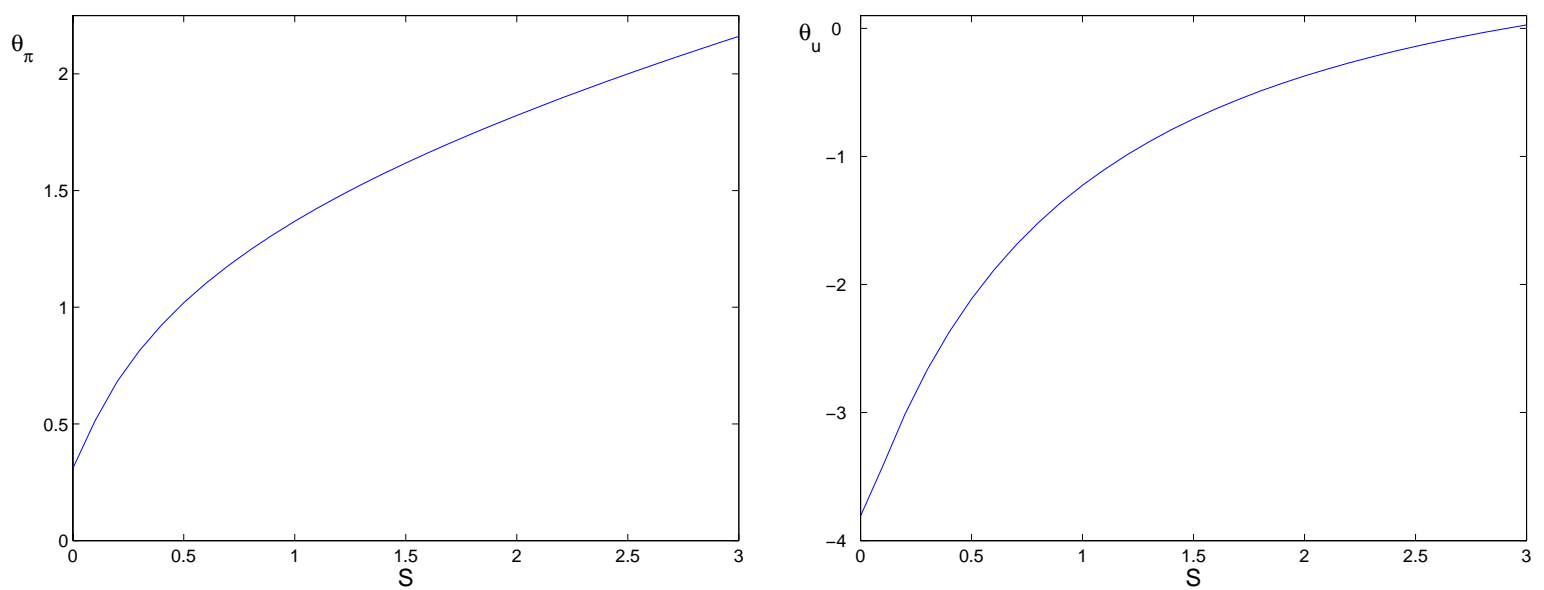

Notes: The lines indicate the optimal choices of the parameters $\theta_{\pi}$ and $\theta_{u}$ in the policy rule: $f_{t}=r_{t}^{*}+\pi_{t}+\theta_{\pi}\left(\pi_{t}-\pi^{*}\right)+\theta_{u}\left(u_{t}-u_{t}^{*}\right)$ for different degrees of misperceptions regarding the natural rates, $s$. 
Figure 7

\section{Performance with Optimized and Robust Taylor Rules for Given Degrees of Natural Rate Misperceptions}
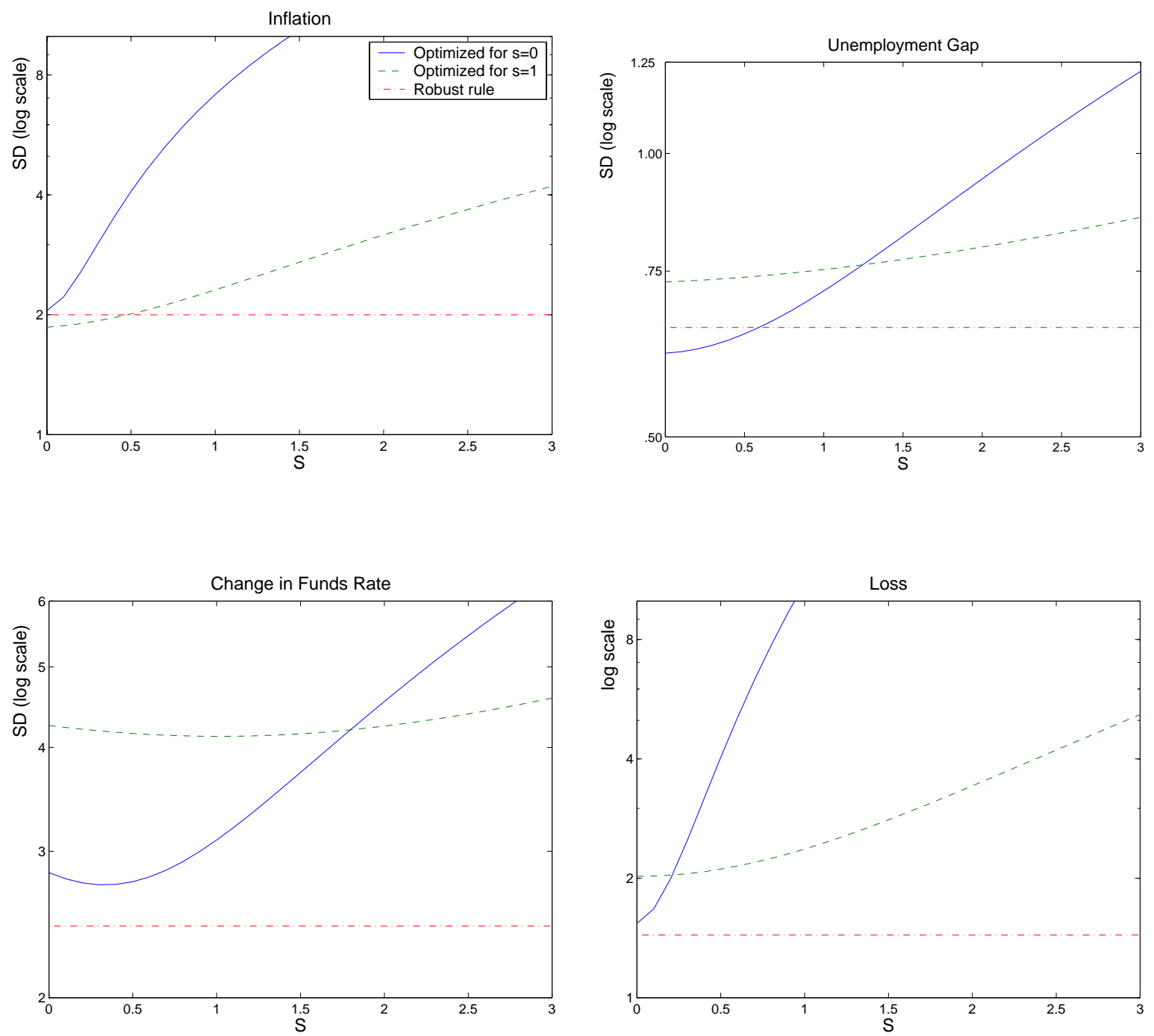

Notes: The three lines in each panel show the asymptotic standard deviations/loss (vertical axes) corresponding to the degree of misperceptions regarding the natural rates, $s$ (horizontal axis) for three alternative policy rules: the Taylor rule (1) optimized with the assumption that $s=0$ (solid lines); the Taylor rule (1) optimized with the assumption that $s=1$ (dashed lines); and the robust rule (3) (dash-dot lines). 
Figure 8

Optimal Policy Response Parameters under Generalized Policy Rules for Given Degrees of Natural Rate Misperceptions
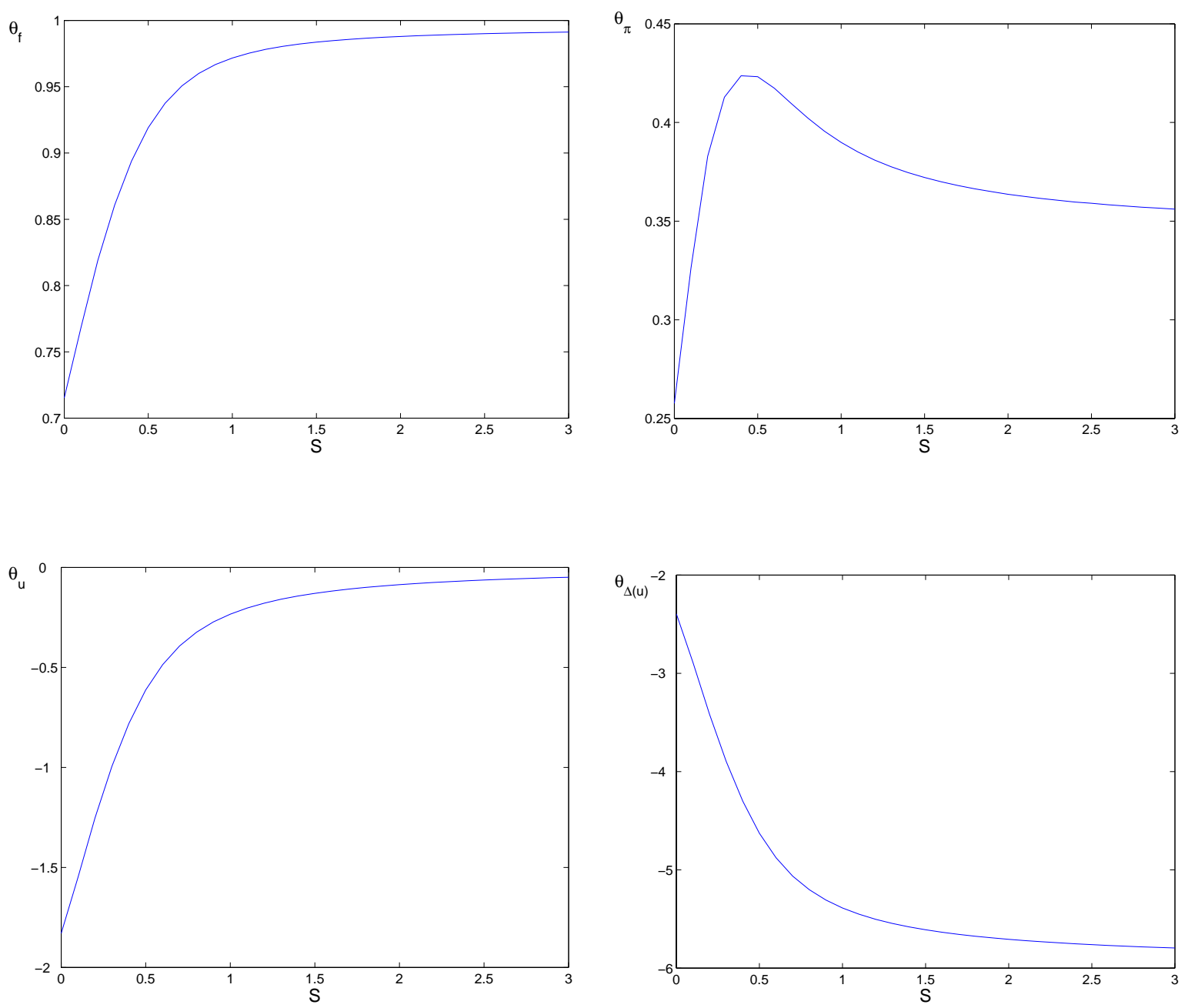

Notes: The lines indicate the optimal choices of the parameters $\theta_{f}, \theta_{\pi}, \theta_{u}$ and $\theta_{\Delta u}$ in the policy rule: $f_{t}=\theta_{f} f_{t-1}+\left(1-\theta_{f}\right)\left(r_{t}^{*}+\pi_{t}\right)+\theta_{\pi}\left(\pi_{t}-\pi^{*}\right)+\theta_{u}\left(u_{t}-u_{t}^{*}\right)+\theta_{\Delta u}\left(u_{t}-u_{t-1}\right)$ for different degrees of misperceptions regarding the natural rates, $s$. 
Figure 9

\section{Performance with Robust and Generalized Taylor Rules for Given Degrees of Natural Rate Misperceptions}
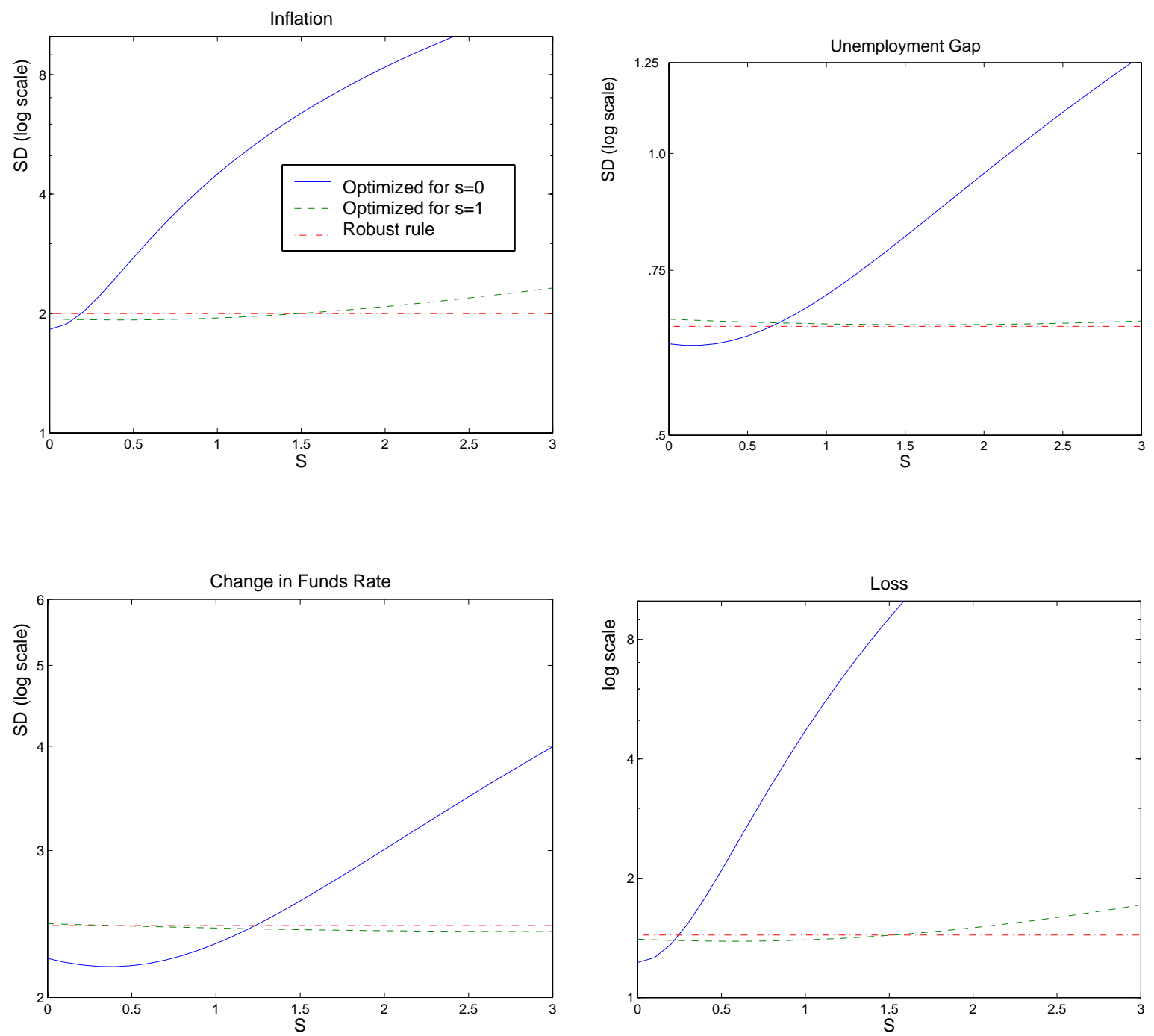

Notes: The three lines in each panel show the asymptotic standard deviations/loss (vertical axes) corresponding to the degree of misperceptions regarding the natural rates, $s$ (horizontal axis) for three alternative policy rules: the generalized rule (2) optimized with the assumption that $s=0$, (solid lines); the generalized rule (2) optimized with the assumption that $s=1$ (dashed lines); and the robust rule (3) (dash-dot lines). 
Figure 10

\section{Efficient Policy Response Parameters under Generalized Taylor Rules for Given Degrees of Natural Rate Misperceptions}

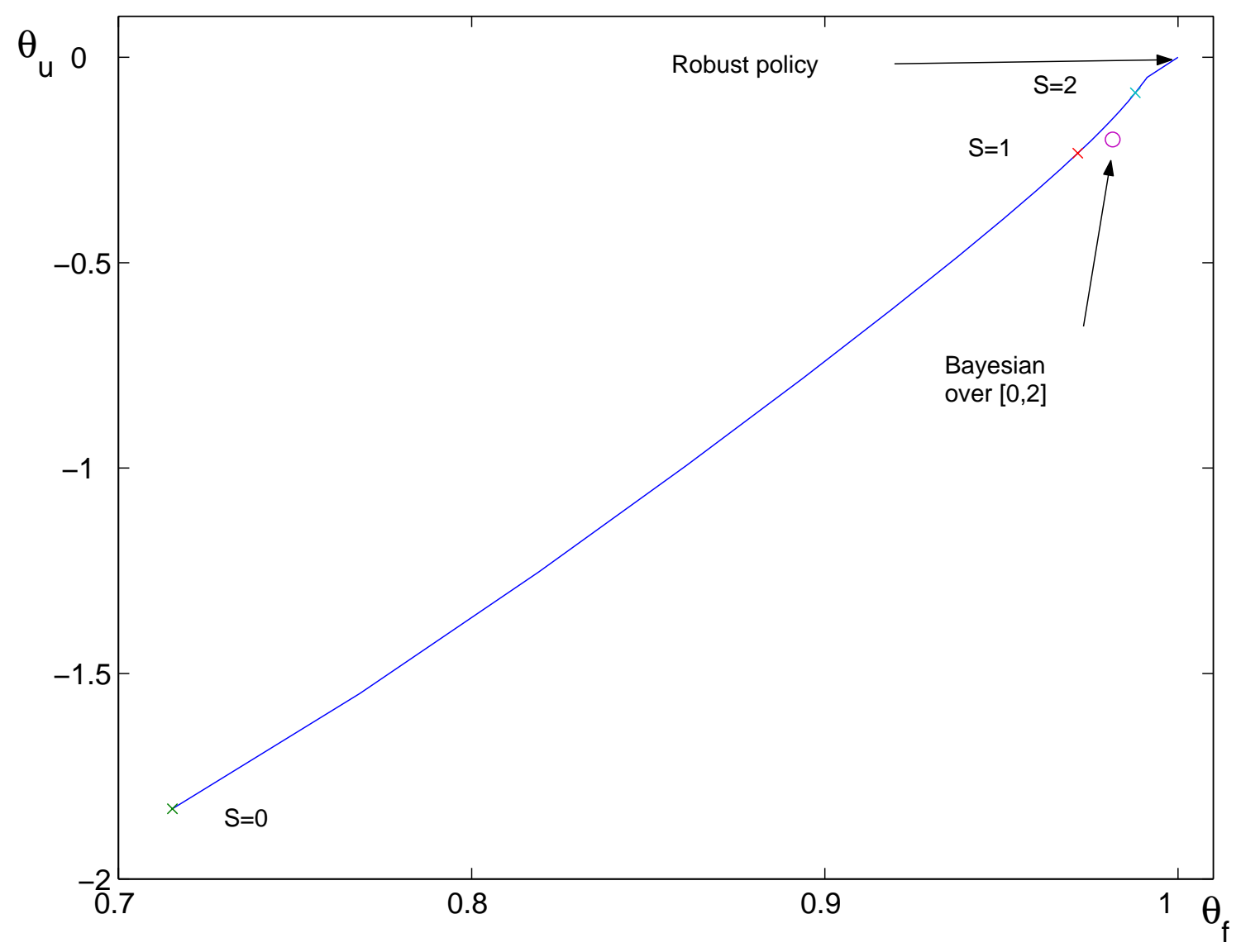

Notes: The solid line traces the pairs of optimal choices of the parameters $\theta_{f}$ (horizontal axis) and $\theta_{u}$ (vertical axis) for different known degrees of misperceptions shown in Figure 10. Movements along the line in the northeast direction correspond to higher values of $s$ and the pairs corresponding to $s=0,1,2$ are marked with an $\mathrm{x}$. "Bayesian" indicates the optimal choices when the policymakers has a uniform prior about $s$ on the $[0,2]$ range. "Robust" indicates our simple difference rule. 
Figure 11

\section{Optimal Policy Response Parameters in New Synthesis Model for Given Degrees of Natural Rate Misperceptions}
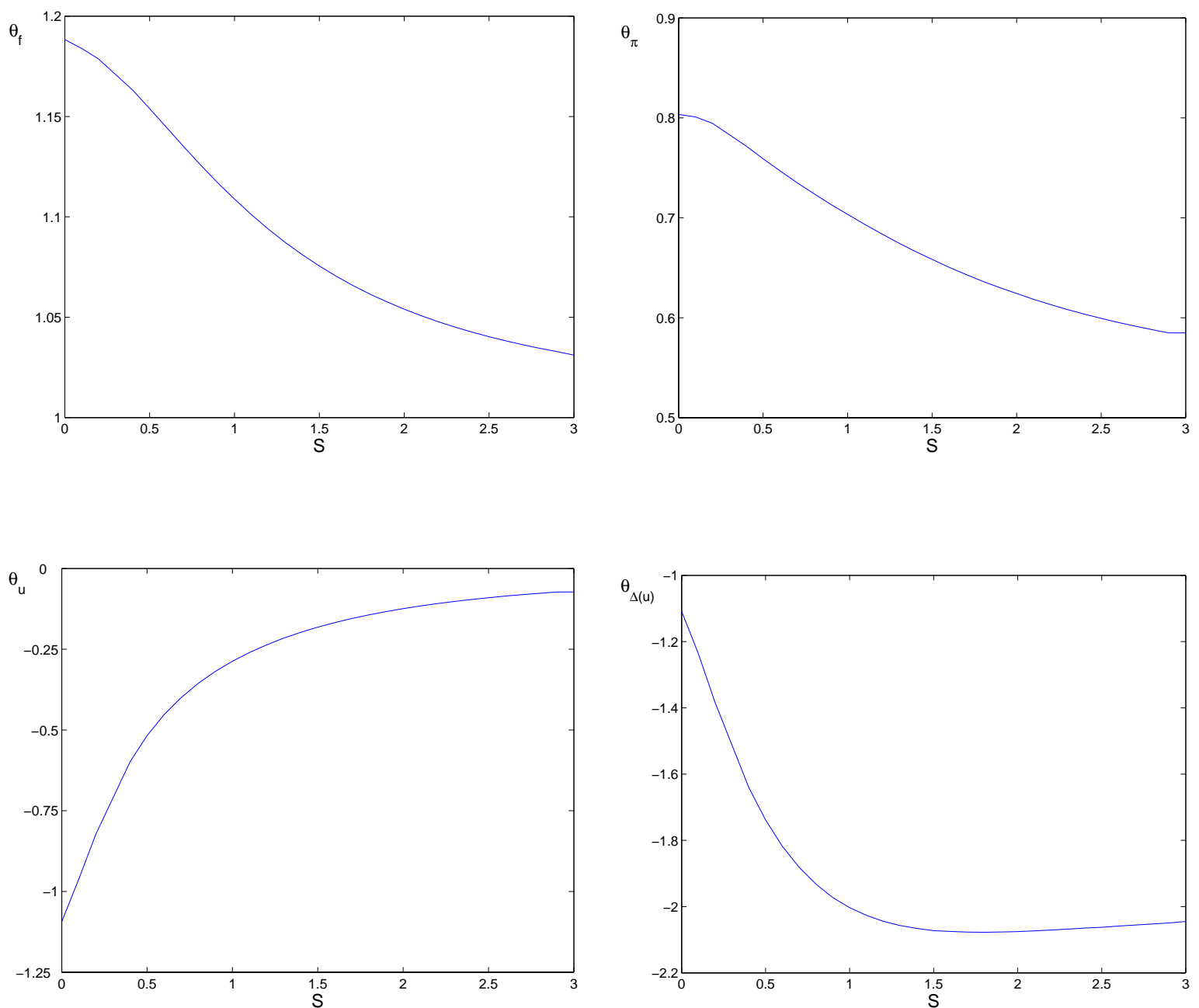

Notes: The lines indicate the optimal choices of the parameters $\theta_{f}, \theta_{\pi}, \theta_{u}$ and $\theta_{\Delta u}$ in the New-Synthesis model when policy follows the rule: $f_{t}=\theta_{f} f_{t-1}+\left(1-\theta_{f}\right)\left(r_{t}^{*}+\pi_{t}\right)+\theta_{\pi}\left(\pi_{t}-\right.$ $\left.\pi^{*}\right)+\theta_{u}\left(u_{t}-u_{t}^{*}\right)+\theta_{\Delta u}\left(u_{t}-u_{t-1}\right)$ for different degrees of misperceptions regarding the natural rates, $s$. 
Figure 12

Optimal Policy Response Parameters in Accelerationist Model for Given Degrees of Natural Rate Misperceptions
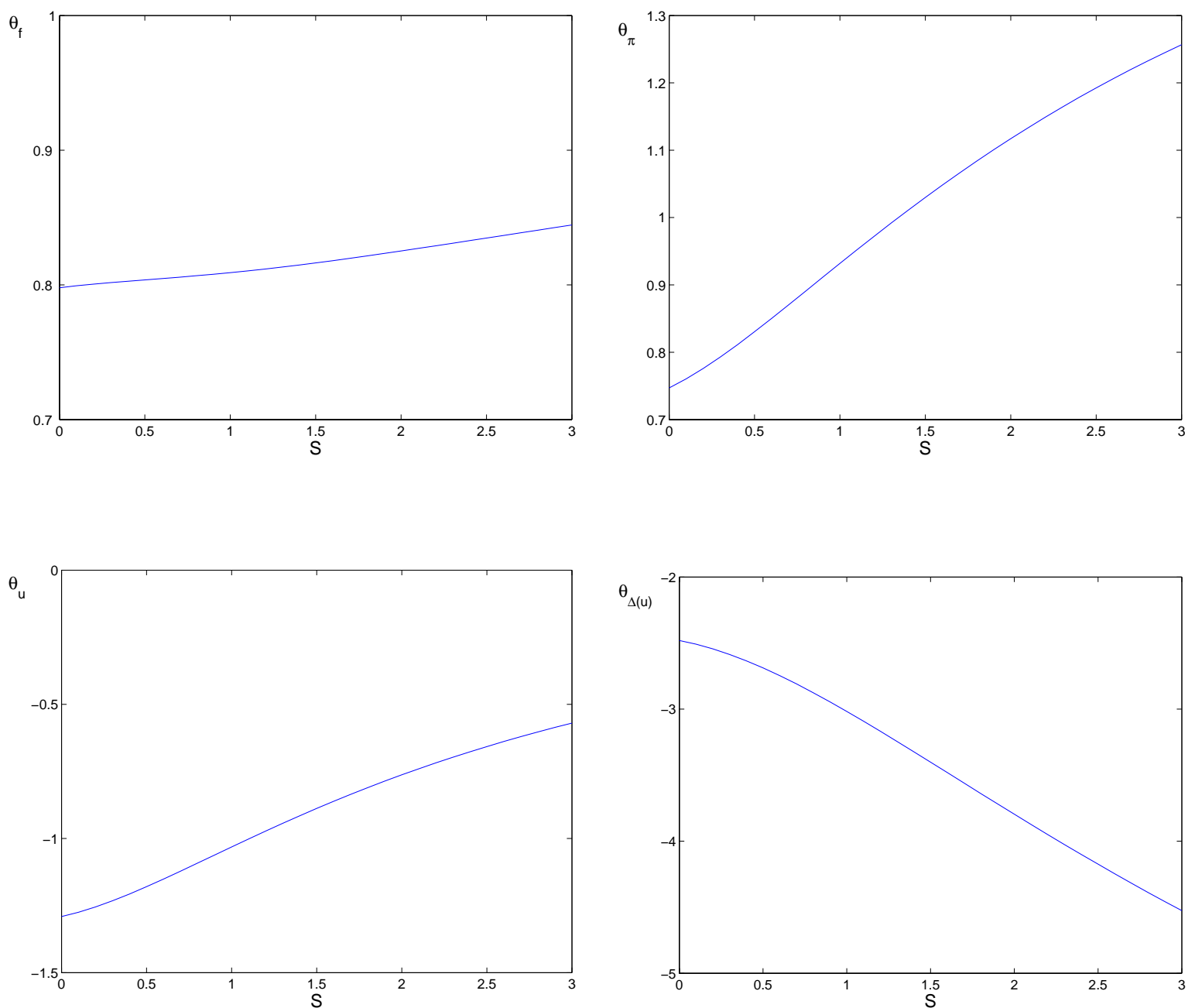

Notes: The lines indicate the optimal choices of the parameters $\theta_{f}, \theta_{\pi}, \theta_{u}$ and $\theta_{\Delta u}$ in the accelerationist model when policy follows the rule: $f_{t}=\theta_{f} f_{t-1}+\left(1-\theta_{f}\right)\left(r_{t}^{*}+\pi_{t}\right)+\theta_{\pi}\left(\pi_{t}-\right.$ $\left.\pi^{*}\right)+\theta_{u}\left(u_{t}-u_{t}^{*}\right)+\theta_{\Delta u}\left(u_{t}-u_{t-1}\right)$ for different degrees of misperceptions regarding the natural rates, $s$. 
Figure 13

\section{Misperceptions of Natural Rates Following an Unexpected Increase}
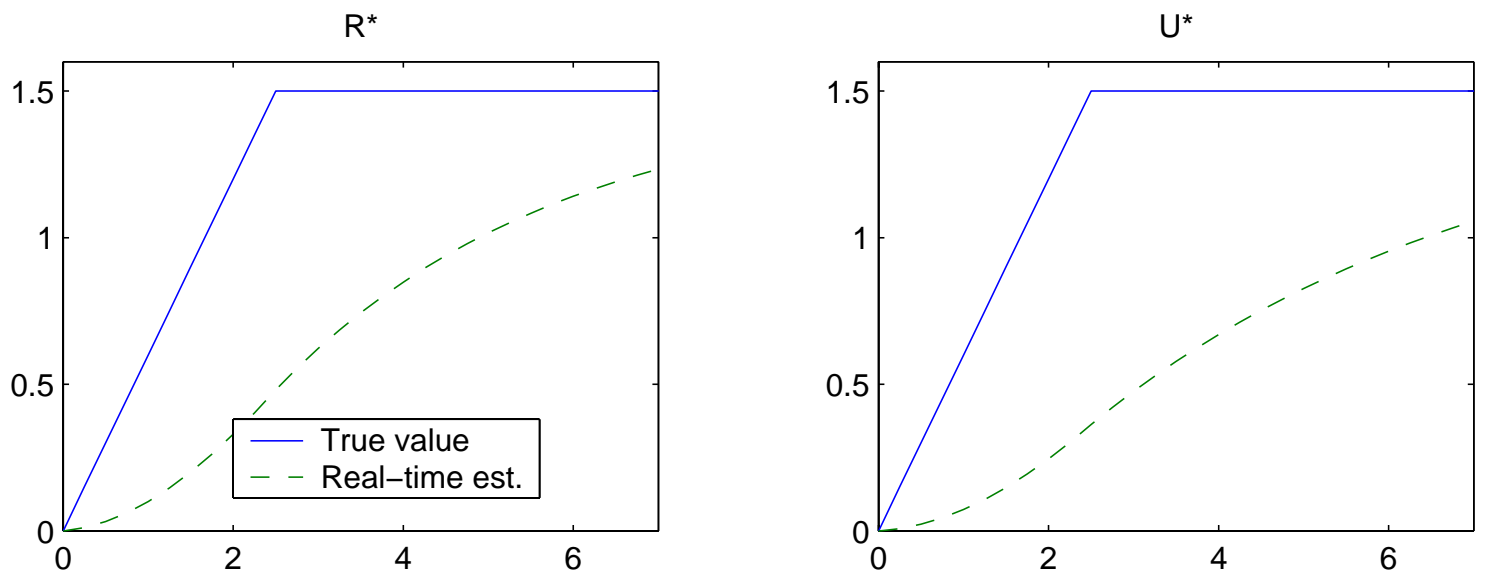

Real-time $\mathrm{R}^{*}$ Errors

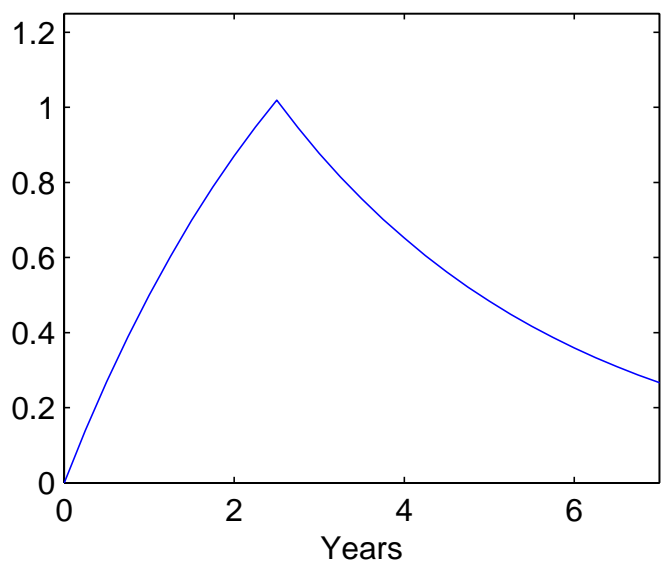

Real-time U* Errors

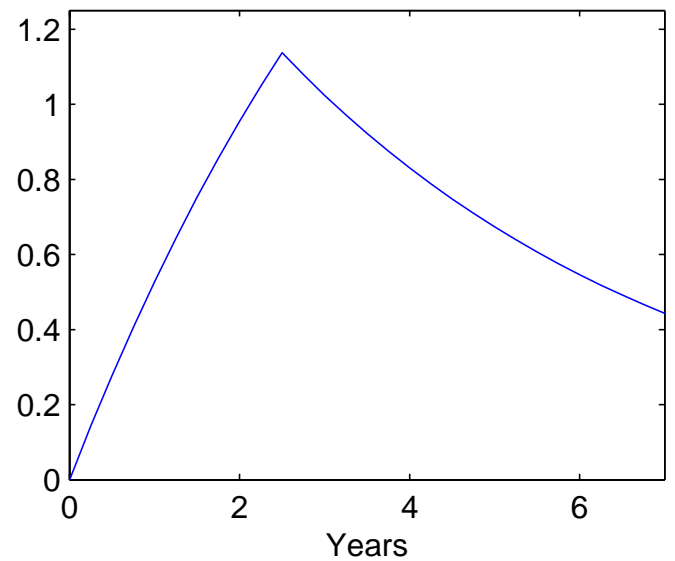

Notes: The top panels indicate the evolution of the true and perceived natural rate of interest (left) and unemployment (right) over time, following a series of unanticipated increases in the natural rates which cumulate to 1.5 percentage points over a period of 10 quarters (2 $1 / 2$ years). The bottom panels trace the resulting evolution of misperceptions about the natural rates over time. In all panels, we plot deviations from steady state values, in percent. 
Figure 14

\section{Performance under Taylor Rules Following a Misperceived Increase in Natural Rates}
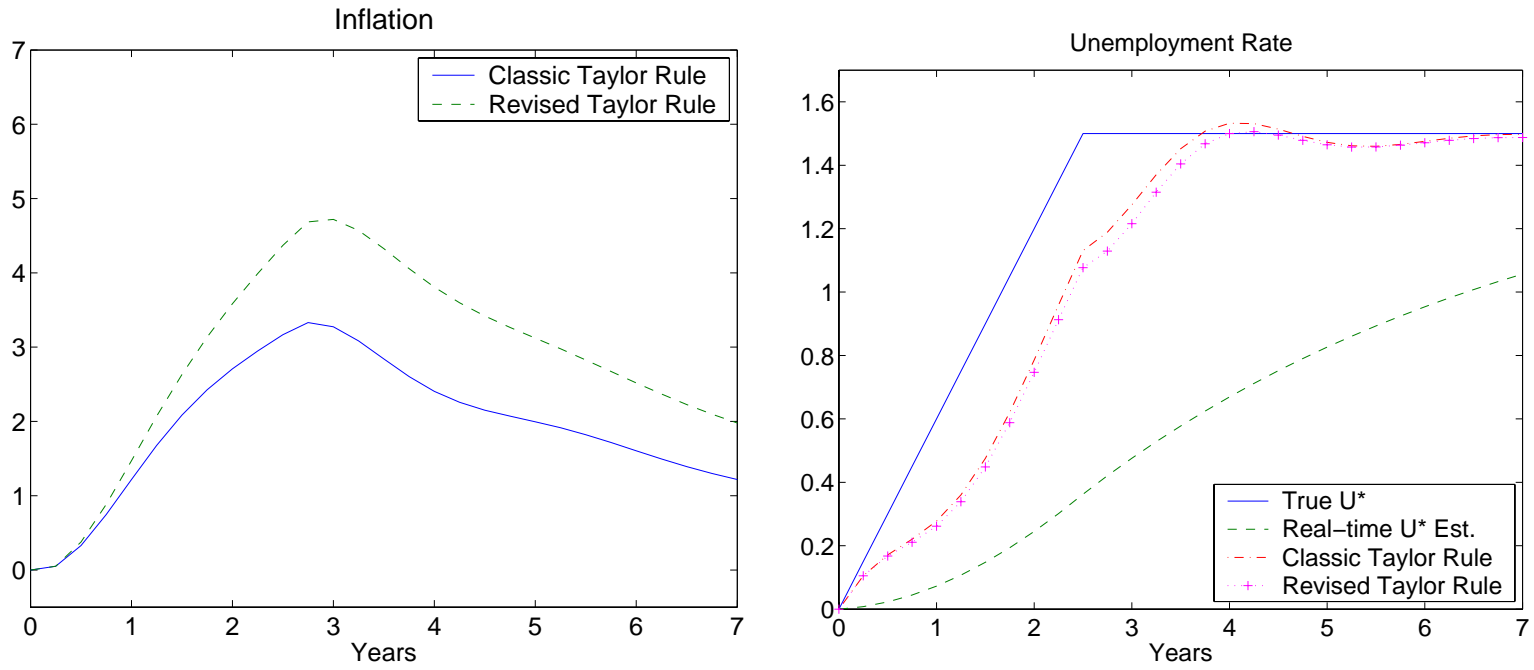

Notes: The two panels trace the evolution of inflation and unemployment (deviations from steady state values, in percentage points) in an economy subjected to the unexpected increases in the natural rates of interest and unemployment shown in Figure 13 for the classic and revised versions of the Taylor rule. 
Figure 15

\section{Performance under Optimized Generalized and Robust Rules Following a Misperceived Increase in Natural Rates}
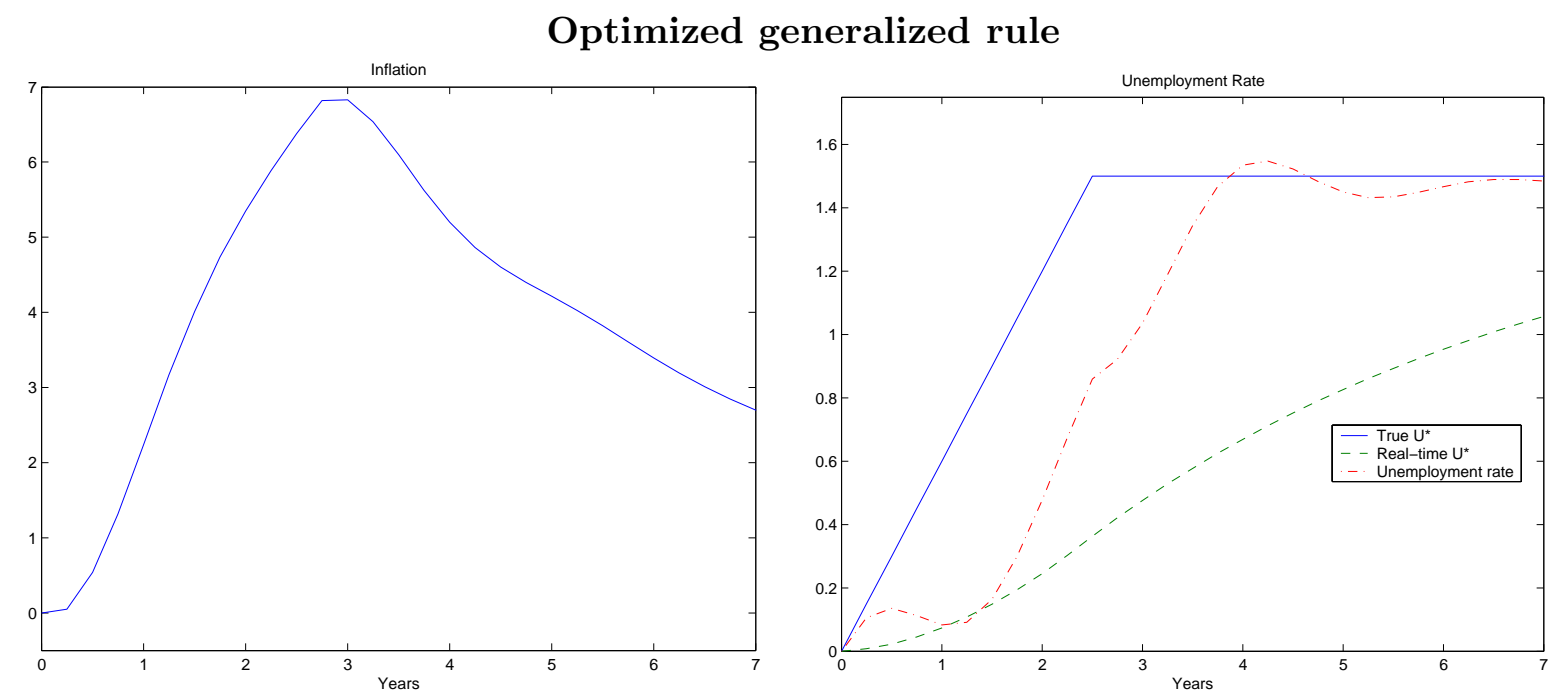

\section{Robust Rule}
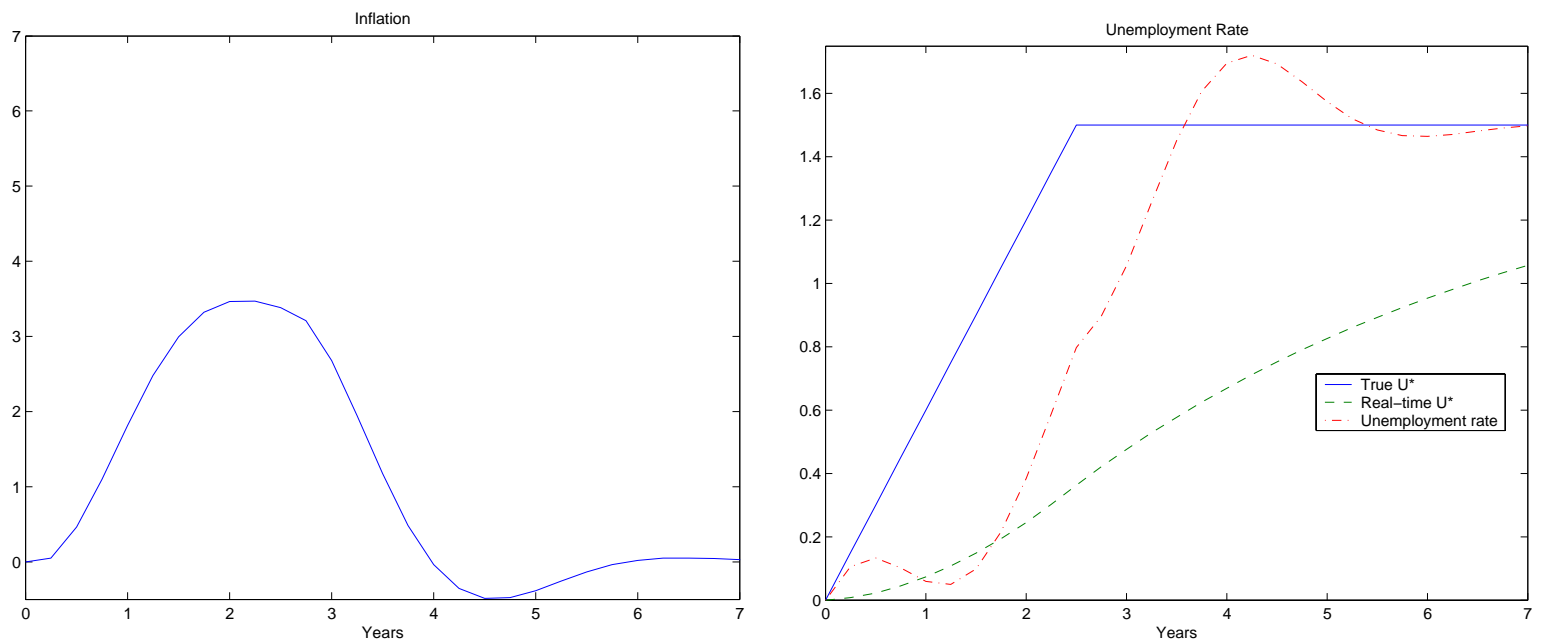

Notes: The top and bottom panels trace the evolution of inflation and unemployment in an economy subjected to the unexpected increases in the natural rates of interest and unemployment shown in Figure 13 for two alternative policies: The optimized generalized rule for $s=0$ (row 17 in Table 2) shown in the top panels, and the robust rule (row 25 in Table 2) in the bottom panels. In all panels, we plot deviations from steady state values, in percent. 
Figure 16

\section{Performance under Optimized Generalized and Robust Rules Following a Misperceived Decrease in the Natural Rate of Unemployment}
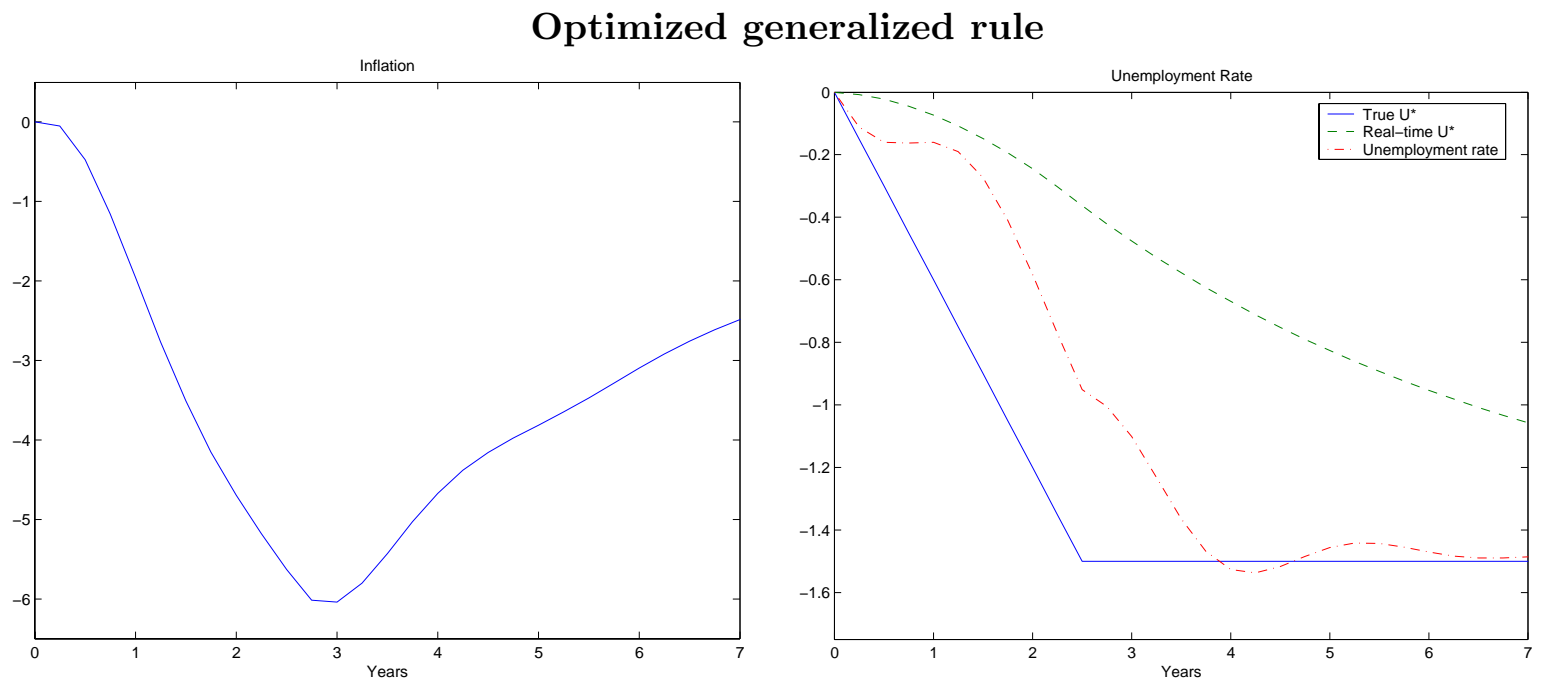

Robust Rule
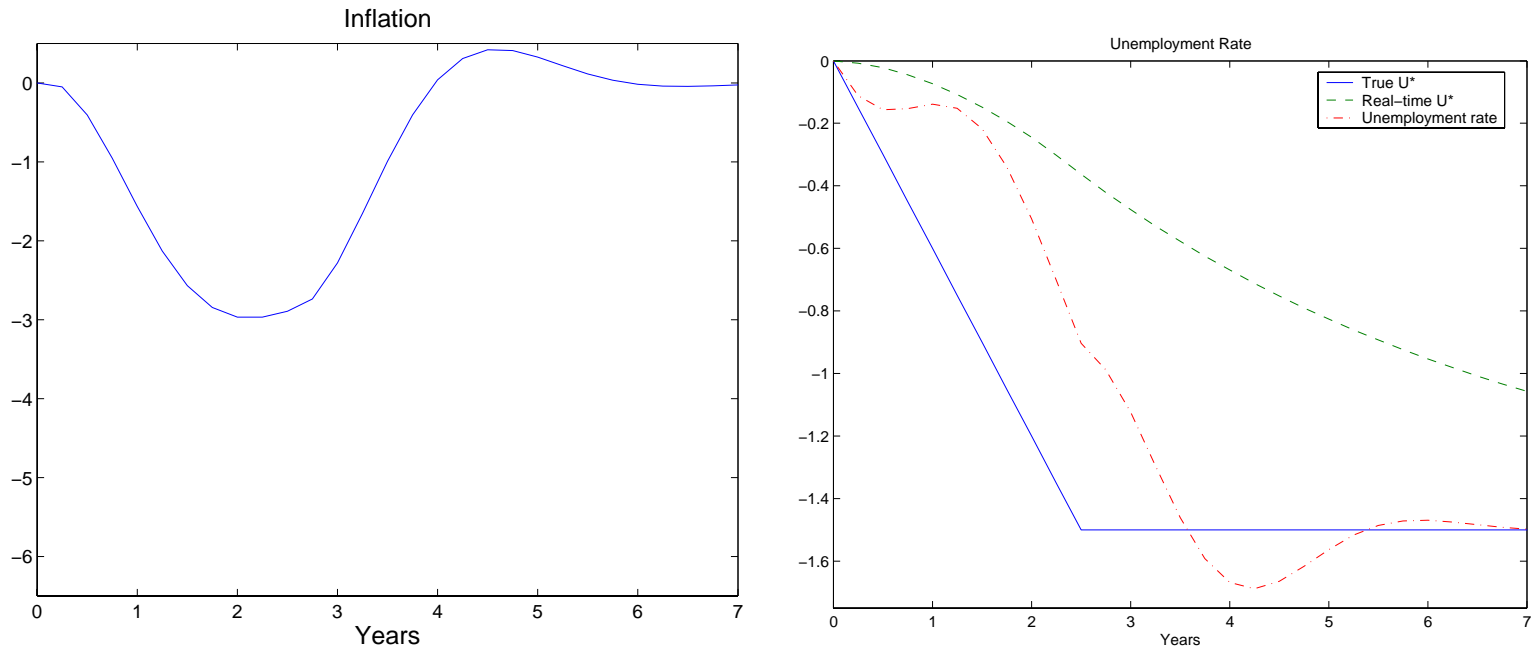

Notes: The top and bottom panels trace the evolution of inflation and unemployment in an economy subjected to an unexpected decrease in the natural rate of unemployment for two alternative policies: The optimized generalized rule for $s=0$ (row 17 in Table 2) shown in the top panels, and the robust rule (row 25 in Table 2) in the bottom panels. For this experiment, we assume that the natural rate of interest remains unchanged and that the change in the natural rate of unemployment has the the same size and timing but reverse sign of that shown in the right panels of Figure 13. In all panels, we plot deviations from steady state values, in percent. 